DIW BERLIN

Discussion

Papers
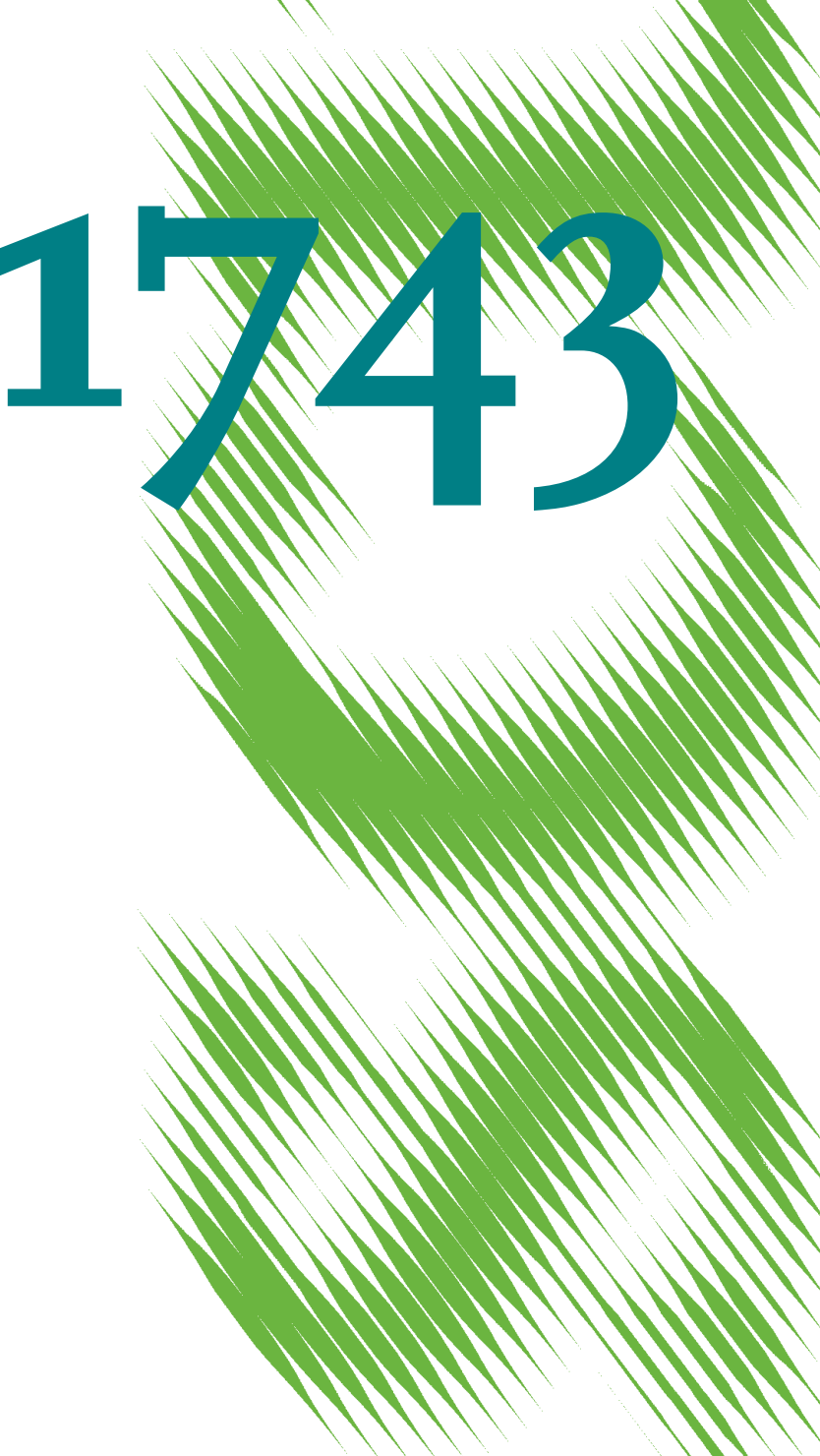

MMMMMMMMMT

Active Learning Fosters Financial Behavior

Experimental Evidence 
Opinions expressed in this paper are those of the author(s) and do not necessarily reflect views of the institute.

IMPRESSUM

(C) DIW Berlin, 2018

DIW Berlin

German Institute for Economic Research

Mohrenstr. 58

10117 Berlin

Tel. +49 (30) $89789-0$

Fax +49 (30) $89789-200$

http://www.diw.de

ISSN electronic edition 1619-4535

Papers can be downloaded free of charge from the DIW Berlin website:

http://www.diw.de/discussionpapers

Discussion Papers of DIW Berlin are indexed in RePEc and SSRN:

http://ideas.repec.org/s/diw/diwwpp.html

http://www.ssrn.com/link/DIW-Berlin-German-Inst-Econ-Res.html 


\title{
Active learning fosters financial behavior: Experimental evidence
}

\author{
Tim Kaiser and Lukas Menkhoff
}

\begin{abstract}
We conduct a randomized field experiment to study the effects of two financial education interventions offered to small-scale retailers in Western Uganda. The treatments contrast "active learning" with "traditional lecturing" within standardized lesson-plans. We find that active learning has a positive and economically meaningful impact on savings and investment outcomes, in contrast to insignificant impacts of lecturing. These results are not conditional on prior education or financial literacy. The active learning intervention seems to be superior as it works via three cognitive and non-cognitive mechanisms, i.e. increased financial knowledge, self-control, and financial confidence, while lecturing only affects financial confidence.
\end{abstract}

JEL-Classification: O16 (savings), D14 (personal finance), I21 (analysis of education) Keywords: financial behavior, financial literacy, active learning, lecturing, training method, field experiment

June 22, 2018

We thank the vendors in Western Uganda for participating in our study as well as all the project members at Mountains of the Moon University, Fort Portal (Uganda), especially Robert Mawenu and Oliver Schmidt. We greatly appreciate the Agricultural and Rural Finance Program (AGRUFIN) of the Gesellschaft für internationale Zusammenarbeit (GIZ) in Uganda for generously funding the treatments and data collection. Special thanks go to Dirk Steinwand, Julia Kirya, and Esther Nanjovu. Finally, we appreciate comments from seminar participants in Berlin, Fort Portal, Hamburg, Kampala, Kiel, Washington D.C., and Vienna, in particular Florian Artinger, Toman Barsbai, Christian Biener, Christine Binzel, Shawn Cole, Nathan Fiala, Xavier Giné, Antonia Grohmann, Ralph Hertwig, Anita Mukherjee, Katharina Lehmann-Uschner, Annamaria Lusardi, Pierre-Carl Michaud, Olivia Mitchell, Helke Seitz, William Skimmyhorn, Carly Urban, Lore Vandewalle, William Walstad, Joachim Winter, and Bilal Zia. Financial support by DFG through CRC TRR 190 is gratefully acknowledged. This field-experiment was pre-registered at the AEA RCT Registry on October 10, 2015 (ID: AEARCTR0000906); see: https://www.socialscienceregistry.org/trials/906/history/6694.

Tim Kaiser, University of Koblenz-Landau and German Institute for Economic Research (DIW Berlin), 10108 Berlin, Germany; kaiser@uni-landau.de

Lukas Menkhoff, Humboldt-University of Berlin and German Institute for Economic Research (DIW Berlin), 10108 Berlin, Germany; lmenkhoff@diw.de 



\section{Active learning fosters financial behavior: Experimental evidence}

\section{Introduction}

Financial education programs are expected to foster the financial literacy and behavior of individuals in order to achieve financial inclusion and to promote financial development. However, the potential impact of these programs is debated in the literature (see Hastings et al., 2013; Lusardi and Mitchell, 2014; van Roij et al., 2014; Brown et al., 2016; Cole et al. 2016) because early experiments show relatively muted effects on financial outcomes (e.g. Cole et al., 2011). While more recent evidence clearly tilts toward the intended effectiveness (Kaiser and Menkhoff, 2017), the causal effects of these interventions are economically small on average (cf. Fernandes et al., 2014). Moreover, effects seem to be highly heterogeneous across multiple dimensions (Miller et al., 2015; Kaiser and Menkhoff, 2017). As even largescale financial education programs appear to have only modest effects on financial behavior (cf. Bruhn et al., 2014, 2016), policymakers and researchers are evaluating alternatives and complements to the typical and pervasive lecture-based classroom-programs (cf. Drexler et al., 2014; Carpena et al., 2011, 2017; Campos et al., 2017).

Many of these efforts to increase the effectiveness of financial education involve either tailoring the intervention to narrow target groups (Drexler et al., 2014) or introducing personalized elements (Carpena et al., 2017). Personalization, however, implies a low student to teacher ratio that is costly and difficult to operate at scale. In contrast, we study an intervention targeting a more general audience and keeping the participant to teacher ratio unchanged, only changing how the content is taught. While the advantage of "active learning" over "traditional lecturing" is empirically demonstrated in other domains, such as science instruction (e.g., Deslauriers et al., 2011; Ruiz-Primo et al., 2011; Freeman et al., 2014; 
Wieman 2014), no study experimentally examines the effects of how financial education content is taught. Moreover, we examine the effect of education on field behaviors (not just on knowledge), which is another novelty in the active learning literature. Interactive teaching methods that engage and involve participants are expected to yield greater impacts than the exposition centered financial education that currently dominates many programs. Thus, we conduct a large-scale cluster-randomized field experiment to examine the treatment effects of this alternative approach to financial education. The financial education treatments contrast an active learning approach with a traditional lecturing approach, while teachers, content, and intensity of training are kept constant. The randomized field-experiment is conducted in rural Western Uganda with 1,291 market vendors.

Three results emerge: First, and our main finding, is that the group allocated to the active learning program experiences a significant improvement in financial behavior; this means an increase in three out of five desired outcome-domains, each captured by an index. The strongest impacts occur in the savings and investment domains: total savings increase by 21 percent relative to the control group, with active learning having a direct effect on investments into the own business and business formalization. In addition, there are weaker, but still marginally significant, effects on an index of debt-related behavior. Thus, this approach generates larger treatment-effects than the insignificant, positive treatment effects realized by traditional lecturing. Moreover, differential treatment effects can be confirmed for outcomes in the savings domain.

Second, we provide tentative evidence that the relatively strong impact of the active learning approach relies on activating several channels: the savings outcome is not primarily caused by an increase in financial literacy but is impacted through the channel of increased self-control. Investment outcomes, in contrast, appear to be impacted through increased financial literacy and changes in financial confidence. 
Third, we show in heterogeneity analyses that the benefits of active learning are generally not conditional on low levels of prior education or financial literacy. This is in contrast to other studies where training is mainly effective for relatively low-skilled individuals (Bjorvatn and Tungodden, 2010; Drexler et al., 2014; Fort et al., 2016).

Our research adds to the growing literature that advances the understanding of the differing impact of delivery channels of financial education and seeks to contribute to the debate on how to design effective financial education interventions. Drexler et al. (2014), varying the content of the financial education curriculum, show the differential impacts of two different financial education curricula in the Dominican Republic. They provide evidence that a heuristics-based approach, relying on the simplification of complex financial concepts ("rule-of-thumb-training"), generates larger behavioral impacts than the teaching of traditional curricula ("full technical training"), mainly for low-skilled individuals and individuals with low baseline financial literacy and motivation. Skimmyhorn et al. (2016) rerun this type of experiment, but do not find evidence to support differential effects regarding the two different types of curricula, probably because their sample of respondents has high levels of ex-ante human capital, confirming the result by Drexler et al. (2014) that the benefits of the "rule-of-thumb" approach may be driven by strong effects on low-skilled individuals. Lusardi et al. (2017) present evidence from online-experiments conducted in the U.S. that interactive tools, narratives, and financial education videos may be more effective than written informational content in affecting financial knowledge and self-efficacy.

Meanwhile, Berg and Zia (2017) show that financial education interventions that primarily target non-cognitive channels through mass media can significantly impact financial behavior. Campos et al. (2017) demonstrate that a psychology-based training program for entrepreneurs, teaching a pro-active mindset, outperforms traditional business training for self-employed individuals in West Africa with strong differential effects on business profits. 
Finally, Carpena et al. (2017) show in a multiple-treatment experiment that complementing traditional instruction with personalized elements, like counselling and goal-setting, yields higher treatment effects on financial behaviors, such as keeping track of household expenses through a written budget, starting (informal) savings, and avoiding expensive borrowing to cope with unexpected shocks.

Much of this evidence suggests that interventions relying on traditional lecturing within classroom-settings appear to have small or zero effects. Thus, alternative approaches to lecture-based education seem to be especially important when targeting low-skilled and lowincome individuals. Some argue that "one-size-fits-all" (Drexler et al., 2014, p. 25; Carpena et al., 2017 p.2) classroom programs are not suitable for fostering financial behavior and programs must be complemented with individualized elements. We show that even within a one-size-fits-all classroom program, active learning techniques can provide the missing link between knowledge creation and behavioral change. Encouragingly, results are not conditional on low prior human capital. While exposition centered teaching methods may impact the financial literacy of those with very low ex-ante financial literacy, it yields much smaller treatment effects in general and does not significantly impact financial behavior, thus confirming the aforementioned results of prior literature on exposition-centered classroom programs.

This paper is structured into seven further sections: Section 2 describes the financial education programs, the experimental design, and empirical strategy. Section 3 provides an overview over response rates, descriptive statistics, and a discussion of randomizationbalance. Section 4 presents main results. Section 5 provides a discussion of potential causal mechanisms leading to behavioral change. Section 6 presents an investigation of distributional treatment effects and treatment effect heterogeneity. Section 7 summarizes robustness exercises and Section 8 discusses the results and concludes. 


\section{Treatments and experimental design}

In this section we describe the two financial education programs (Section 2.1), the experimental design (Section 2.2), and the empirical strategy employed (Section 2.3).

\subsection{Financial education interventions}

As a step toward promoting financial inclusion, the Bank of Uganda $(B o U)$, the country's central bank, established a national strategy for financial literacy in Uganda. ${ }^{1}$ This strategy seeks to foster the personal financial knowledge and behavior of different target groups, including school students, young adults in urban settings, and adults in rural areas. The $B o U$ partnered with the German Development Cooperation (GIZ) to design effective financial education interventions. While the specific curricula and dissemination formats vary depending on the target group, they all target financial knowledge and behavior within the five sub-domains of (i) budgeting and personal financial management, (ii) credit, (iii) savings, (iv) business investing, and (v) payments and financial service providers.

Focusing on one of the financial education strategies' major objective of improving rural outreach, GIZ developed educational formats for the target population of the rural selfemployed. These programs teach how to create a written household budget and how to keep track of household's financial inflows and outflows; they also encourage household savings, explain the costs and benefits of various forms of credit, explain the trade-off between risk and return regarding productive investments into micro-enterprises, highlight the benefits of diversification among sources of income and investments, and inform about the benefits of using financial services provided by regulated financial institutions. Thus, this training promotes the use of formal financial services, without generally discouraging semi-formal

\footnotetext{
${ }^{1}$ See: https://www.bou.or.ug/opencms/bou/bou-downloads/Financial_Inclusion/Strategy-for-Financial-Literacyin-Uganda_August-2013.pdf; last accessed February 9, 2018.
} 
types of financial products (e.g. saving in village savings and loans associations (VSLAs) or rotating savings and credit associations (ROSCAs)). The trainings do, however, caution against both the use of expensive credit provided by informal money-lenders and the take up of costly loans to finance consumption expenditures in general.

Currently, among other interventions, GIZ offers two different educational interventions for the same target group of rural self-employed, creating the opportunity to study the differential impact of alternative delivery approaches to financial education. While these two programs are identical with regards to the content areas covered (they both address the domains (i) to (v)) and their intensity (120 minutes), they differ in their concrete method of instruction, i.e. how this content is taught (cf. Table A1 in Appendix A).

Version A of the financial education training uses active learning methods and is highly learner-centered (see Ruiz-Primo et al., 2011; Freeman et al., 2014). Its main feature are five distinct stations, designed to provide problem-based learning opportunities and encourage discussion among the participants. Exercises and materials are designed to engage participants with the subject matter, e.g. through completing budgeting exercises, sorting different savings- and investment options with regard to their safety risk/return-profiles, differentiating between sensible and non-sensible reasons to take up a loan, and completing an exercise on whether financial services are regulated by the central bank or not. Respondents are encouraged to share their experiences and complete the exercises. The trainer has the role of a learning facilitator.

Version B, on the other hand, is organized as a community lecture, i.e. an "expositioncentered" (Freeman et al., 2014, p. 8410) traditional lecturing approach, relying mostly on lecturing with the aid of a flip-chart and some room for participants to ask questions. Here, the lecturer explains important concepts and demonstrates how to create a written budget, and how different financial products and choices could be categorized. The participants are 
expected to listen to the input of the trainer and are allowed to ask questions. Sharing of experiences is also encouraged, but the trainer can be characterized as a lecturer rather than a facilitator. Thus, the experiment is designed to contrast constructivist versus expositioncentered (transmissive) course designs as two stylized ideal-types along the continuum of instructional approaches. Despite these important differences in instructional methods, both versions of the financial education training are standardized to cover the same content and to have the same intensity of about two hours. For the purpose of evaluating the impact of the financial education programs, we employ the same group of newly recruited teachers to deliver both financial education versions $\mathrm{A}$ and $\mathrm{B}$ to the target groups. Thus, the different versions are not confounded with idiosyncratic characteristics of the teachers and implementation is not heterogeneous across experimental sites. The teachers are all enrolled in a program on banking and microfinance at a local university and have participated in a training of trainers offered by $B o U$ and GIZ.

\subsection{Experimental design}

We organize a cluster-randomized experiment to study the differential impact of the two financial education interventions on financial behavior. The main outcomes of interest are changes in financial behaviors within five sub-domains addressed by the financial education interventions, i.e. (i) budgeting, (ii) usage and handling of credit, (iii) savings, (iv) business investing and formalization, as well as (v) the use of formal payment- and other financial services such as formal insurance. Randomization is done at the market-level, across 83 rural marketplaces in the seven districts of the Rwenzori Region in Western Uganda, collectively forming the sample of clusters considered in this study (see Figure 1).

$<$ Figure 1 about here $>$ 
To the best of our knowledge, the dataset covers all relevant permanent and regular marketplaces in the region. Because prior information about the marketplaces (such as number of vendors and primary goods traded) is limited at the time of randomization (prior to the individual-level baseline survey), we perform a non-stratified randomization procedure to allocate the 83 clusters in our sample to either receive financial education treatment $A(n=27)$ or B ( $n=28)$, or to be allocated to the control group $(C)(n=28)$. The trainings each aim for reaching a target group of about 15 to 16 vendors, which leads to a sample population of 1,245 to 1,328 individuals.

Vendors were mobilized to participate in our survey and the financial education sessions by the local market-chairpersons. The treatment status was unknown to the marketchairperson, so no differential selection (mobilization) should be in place due to the reliance on local market-chairpersons. However, selection biases could arise if market-chairpersons favor specific groups (such as their peers) over others in general. This would indeed impact the external validity of our experiment in the sense that treatment effects may causally interact with unobserved features of our specific context and sample (cf. Muller, 2015). The internal validity, however, is not affected because these selection mechanisms will occur in all three groups. After baseline survey, the treatment groups received either financial education treatment A (active learning) or B (traditional lecturing) on the same day, immediately after the interviews. The control group (C) did not receive any treatment. After baseline-survey and subsequent financial education treatments, we conducted follow-up surveys approximately 6 months later.

We report power-calculations for minimum detectable effect sizes in order to be able to rule out imprecisely estimated small- or zero-effects of financial education treatment. Intracluster-correlation (ICC) ranges from 0.030 (financial literacy score and budgeting index) to < 0.001 (savings index) for the outcomes. Thus, our experiment has 80 percent power to 
precisely detect (at $\alpha=0.05$ ) effect sizes as small as 0.15 to 0.18 standard deviation units. To put these minimal detectable effect sizes into perspective with results from the most recent meta-analysis of the literature: The average effect size on financial behaviors in a sample of 90 studies is about 0.9 SD units (Kaiser and Menkhoff, 2017). Note that type II error rates are higher than 20 percent for coefficients estimated to be smaller than 0.15 (0.18); i.e. we cannot reject positive impacts of financial education treatments smaller than 0.15 standard deviation units. However, these may be regarded as economically insignificant in our setting (see Section 4).

\subsection{Empirical strategy}

To estimate the causal effect of the financial education interventions on financial literacy and behavior, we compare the two treatment groups $(\mathrm{A}=$ active learning $)$ and $(\mathrm{B}=$ traditional lecturing) with the control group $(\mathrm{C}=$ no treatment $)$ at the time of the follow-up survey. As selection into treatment is randomized, with balanced groups at baseline (see Section 3.2 and Appendix A), the unbiased intent-to-treat (ITT) treatment effect (average effect of being assigned to a treatment-cluster) can be estimated within the following ANCOVA framework (McKenzie, 2012):

$$
y_{i c(t)}=\alpha+\delta_{1} y_{i c(t-1)}+\beta_{1} A_{c}^{T}+\beta_{2} B_{c}^{T}+\theta_{d}+\varepsilon_{i c t}
$$

Here, $y_{i c(t)}$ denotes the outcome variable (measure of financial behavior) for individual $i$ in cluster $c$ at the time of follow-up $(t) . y_{i c(t-1)}$ controls for the lagged value of the outcome at baseline and $\theta_{d}$ are district-level fixed-effects. $A_{i c}^{T}$ and $B_{i c}^{T}$ are dummy variables equal to one for respondents situated in a cluster assigned to treatment $\mathrm{A}$ or $\mathrm{B}$, respectively. Thus, $\beta_{1}$ captures the (ITT) treatment effect of financial education intervention $A$, and $\beta_{2}$ captures the (ITT) treatment effect of intervention $B . \varepsilon_{i c t}$ denotes the error-term. Standard errors are clustered at the market-level to account for the level of randomization. 
For binary outcomes, linear probability models are used (see Karlan and Valdivia 2011, Cole et al. 2013 and Drexler et al. 2014 for this approach). However, results are not sensitive to changing the estimations to non-linear (logit or probit) models for binary outcomes.

To avoid problems inherent to testing multiple hypotheses (type-I-error inflation), we aggregate multiple related outcomes into index-measures of outcomes families: Following Kling et al. (2007), Karlan and Valdivia (2011), and Drexler et al. (2014), we define $y^{*}$ to be an equally weighted average z-score index of its components $y_{k}^{*}$. Thus, for each component of a given outcome-family, we first rescale each outcome such that positive values indicate desirable treatment effects. Next, we standardize the component to have a mean of zero and standard deviation of one for the control-group: $y_{k}^{*}=\frac{y_{k}-\mu_{k}}{\sigma_{k}}$, with $\mu_{k}$ denoting the mean of $y_{k}$ for the control group (C) and $\sigma_{k}$ denoting the standard deviation of $y_{k}$ for the control group. The aggregate index then takes the following form: $y^{*}=\frac{\sum_{k} y_{k}^{*}}{k}$. Finally, we standardize the outcome index $\left(y^{*}\right)$ to have a mean of zero and standard deviation of one for the controlgroup. Thus, coefficients on $A_{i c}^{T}$ and $B_{i c}^{T}$ can be interpreted as standardized mean differences (Glass's $\Delta)$.

Finally, to probe the potential causal mechanisms leading to changes in financial behavior, we follow Sayinzoga et al. (2016) and Bulte et al. (2017) and estimate the following two stage regressions:

$$
\begin{aligned}
& Z_{i c(t)}=\alpha+\beta_{1} A_{c}^{T}+\beta_{2} B_{c}^{T}+\theta_{d}+\varepsilon_{i c t} \\
& y_{i c(t)}=\alpha+\beta_{1} Z_{i c(t)}^{*}+\theta_{d}+\varepsilon_{i c t}
\end{aligned}
$$

Equation (2) shows the first stage of the regressions. Here, $Z_{i c(t)}$ is a measure of intermediate outcomes in a causal chain that may have an impact on downstream behavior. We test three potential mechanisms: $Z_{i c(t)}=$ financial literacy, $\quad Z_{i c(t)}=$ self control, $\quad Z_{i c(t)}=$ financial confidence (see Section 6). The first stage estimates the causal effect of financial 
education treatments $\mathrm{A}$ and $\mathrm{B}$ on these intermediate outcomes. Thus, in the second stage, $Z_{i c(t)}$ is instrumented by the two treatment dummies and we examine whether predicted levels of the intermediate result $\left(Z_{i c(t)}^{*}\right)$ explain variation in financial behavior $\left(y_{i c(t)}\right)$. Note that, although useful to explore the potential causal mechanisms at play, the second stage will not provide an unbiased estimate of the treatment effect. This is due to the fact, that the exclusion restriction is likely to be violated (as suggested by the fact that we consider three possible intermediating variables).

\section{Data}

After mapping of the markets, piloting the survey tools and interventions, and randomization, we conducted a comprehensive baseline survey between November $1^{\text {st }}$ and December $19^{\text {th }}$ of 2015 . This dataset covers all vendors invited and interested to participate in our survey $(n=1,291)$. The questionnaires were translated into three local languages widely spoken in the area and the enumerators conducting the face-to-face interviews in the local languages were trained extensively prior to the field-activities.

\subsection{Response rates}

Following the baseline-survey and the subsequent financial education treatments, we conducted follow-up surveys between April $6^{\text {th }}$ and July $19^{\text {th }}$ of 2016 . After this first round of tracking efforts, we had followed-up with 1,094 vendors (i.e. the attrition rate was at 15.26 percent). To minimize attrition, we undertook extensive tracking efforts to follow up with another 67 respondents (see timeline Figure A1 in Appendix A). Thus, our final response rate is high, given the kind of relatively mobile target group: We follow up with roughly 90 percent of the initial sample at endline survey (see Table 1).

$<$ Table 1 about here> 
Unfortunately, attrition rates vary by experimental condition: While the control group (C) and treatment group (A) have attrition rates of 8.55 percent and 7.25 percent, respectively, the attrition rate in treatment group (B) is almost twice as high as in group (A) at 14.25 percent. While this may indicate selective attrition, we show in comprehensive robustness exercises that this does not affect our results: we probe the sensitivity of our results by estimating bounds on the treatment effects with several scenarios imputing missing observations at the endline and applying inverse probability weighting of selection into endline survey to our regressions. Details are provided in Section 7 and Appendix B.

\subsection{Baseline descriptive statistics}

Table 2 reports summary statistics for the full sample and each experimental condition at baseline (see Table A2 in Appendix A for descriptive statistics for additional baselinecovariates).

$<$ Table 2 about here>

Panel $A$ shows variables that measure characteristics at the household level. The average household size is 6.83 people, with an average of 2.17 adults contributing to the household's income, a mean of 4.17 children being supported and a mean of 0.36 adults who do not generate external income, such as elderly (plus 0.13 for missing values). Several currency denominated outcomes had a long right tail, possibly indicating enumeration errors. Therefore, we winsorize all currency denominated outcomes at the $99^{\text {th }}$ percentile (see e.g. Blattmann et al., 2015 for a study in Uganda). The mean (winsorized) monthly household consumption value is about 593,000 UGX.

Panel $B$ reports variables at the respondent-level. The mean (winsorized) monthly individual income is around 220,000 UGX (about 60 USD). Household consumption is higher than hypothetical added individual incomes because of subsistence farming, as reported by 83 
percent of the sample (see Table A2 in Appendix A). Our sample is predominantly comprised of women ( 80 percent) and the average age is 36.2 years. Only 25 percent report to have participated in education beyond primary school.

Our survey also includes a measure of financial literacy (see Appendix C) and psychological variables, such as self-control and financial confidence, which are standardized to have a mean of zero and a standard-deviation equal to one in the pooled sample (see Appendix A). These are mainly used for the investigation of possible causal mechanisms (see Section 5) and for the purpose of probing randomization balance at baseline.

Panel $C$ shows descriptive statistics for outcome measures of financial behavior indices (standardized to have a mean of zero and a standard deviation equal to one) at baseline (see descriptive statistics for individual index components in Table A3 in Appendix A).

\subsection{Randomization balance}

Causal inference within the estimation framework introduced in Section 2.4 rests on the random assignment of cluster to the treatment conditions, which achieves balanced observed and unobservable characteristics. Randomization balance is probed by comparing the means between the control group and the treatment groups, as reported in columns (4) and (6) of Table 2. These differences are estimated within a simple regression framework, where standard errors are clustered at the market-level. Due to randomization, only a small difference exists: The treatment groups are estimated to be slightly younger, on average, than the control group. However, this difference is only significant at the 10-percent-level (see Appendix A for further baseline covariates which support this picture). This minor imbalance is what can be expected to occur by chance. Panel $C$ shows descriptive statistics for these outcome indices of financial behavior at baseline. Again, no statistically significant differences exist between the three experimental groups (see Table A3 in Appendix A for 
descriptive statistics and randomization balance for single index components). Reassuringly, a joint test of orthogonality (where a categorical variable indicating the experimental group is regressed on all baseline covariates and the index-measures for outcomes at baseline) results in low explanatory power and a p-value of 0.79 . Thus, orthogonality and balance are reassured using this test and a reduced sample of 886 respondents due to missing values for some of the covariates.

\section{$4 \quad$ Results}

This section reports on the main treatment effects of the two financial education interventions (Section 4.1) and detailed analyses of treatment effects on selected index components (Section 4.2).

\subsection{Main treatment effects}

Table 3 reports the average (intent-to-treat) treatment effects of the financial education treatments (A) and (B) on five domains of financial behavior. All coefficients are estimated within an ANCOVA framework and include district-fixed-effects to account for district-level unobservable characteristics (see Appendix B for a discussion of district-level events that suggest including these district dummies).

<Table 3 about here>

Indices of financial behavior. The five domains of financial behavior addressed by these trainings are each measured by an index and are presented in Table 3 in the order of the content areas addressed in the financial education sessions. The indices aggregate the single items as they are presented fully in the Appendix A and selectively discussed in Section 4.2. Overall, coefficients are consistently positive, indicating that financial behavior can be impacted into the intended direction. 
Among these domains of financial behavior, the overall effects are strongest for the investment index with effect sizes being large (more than a quarter of a standard deviation) and statistically significant at the 1-percent-level (column 4). Only treatment A results in a statistically significant change in behavior, here investment behavior. Treatment B, i.e. lecturing, is estimated to have a statistically insignificant effect size of about 0.17 standard deviation units. Because the experiment is powered to detect effect sizes as low as 0.15 standard deviation units for outcomes with low ICC, we conclude that this is evidence of zero-effects of treatment B.

Similarly, the effect on the savings behavior index (column 2) is sizeable for treatment A (about 0.16 standard deviation units) and statistically significant at the 5-percent-level. Again, treatment A has a positive effect, while treatment B is statistically and economically insignificant (effect size of 0.01). The resulting large difference between both trainings generates a statistically significant difference of treatment A over treatment B.

Somewhat surprisingly, relative to low expectations from the literature on the effectiveness of financial education to change debt behavior (Miller et al., 2015; Kaiser and Menkhoff, 2017), we find a small but marginally significant effect for treatment A (column 3). As the coefficient sign of treatment $B$ is even negative, the difference between both treatments is marginally significant, as well. Regarding training effects on the budgeting index (column 1), the effect sizes are positive but statistically insignificant from zero. The coefficient levels are higher for the financial services index (column 5); this is the only case where the coefficient of treatment $\mathrm{B}$ is higher than the one of treatment $\mathrm{A}$, but both coefficients are estimated with a large standard error and remain statistically insignificant.

Overall, we see that financial education tends to have desired effects, but effect sizes remain small and statistically insignificant unless the active learning program is implemented. Active learning results in a significant effect on three out of five financial behaviors addressed by the 
training. Lecturing, on the other hand has no effect any of the addressed financial behaviors. However, meaningful differential treatment effects can only be confirmed for outcomes in the savings domain.

\subsection{Effects on single index components}

This section complements the summary results on indices from above by providing and discussing results about the single index components of interest and considering their economic significance in terms of financial outcomes. In this respect, we focus on those two indices of financial behavior where we found statistically significant results at the 5-percentlevel, i.e. savings and investments outcomes, while the other program objectives (budgeting behavior, debt behavior, and financial services behavior) are discussed in more detail in Appendix A.

Components of the savings index. As shown above, active learning positively affects the savings-index, which is both statistically different from zero and from traditional lecturing (treatment B). Now we look at the three detailed results on financial outcomes as they are aggregated in the index, i.e. "any savings," "total savings," and "net savings." These results are shown in the first three columns of Table 4.

$<$ Table 4 about here>

Given that 87.8 percent of the control group report any savings, the increase due to financial education has to be modest by definition and is, in effect, just 3.8 percentage points for treatment A, which is statistically significant at the 10-percent-level (column 1). The effect of treatment $\mathrm{B}$ is smaller in size at 2.7 percentage points and, thus, statistically insignificant. While this effect size may be economically modest, it is noteworthy that financial education has an effect on savings at the extensive margin that is similar to other studies in various contexts (e.g. Duflo and Saez, 2003; Drexler et al., 2014; Jamison et al., 
2014). Thus, one may speculate whether treatment effects on the extensive margin may be larger in magnitude for samples with lower ex-ante numbers of savers. The main index components driving the overall positive treatment effect of the index, however, are strong increases in financial outcomes in the form of total savings and net savings at the intensive margin.

Respondents in treatment group A report an average increase of 109,186 UGX in total savings, which amounts to a treatment effect of approximately 0.18 standard deviation units, or an increase in savings by 21 percent over the mean of the control group (column 2). In contrast, the effect of treatment B is estimated to be economically small (with a negative sign) and is estimated to be statistically insignificant. Testing for differential impacts, active learning is more successful than traditional lecturing $(\mathrm{p}=0.052)$. The effect on net-savings appears to be even stronger. This variable captures the moderate reduction in debt volume together with the strong positive treatment effect on total savings so that net savings increase by 145,480 UGX (38 percent) relative to the control group (column 3 ). Thus, this effect appears quite strong and statistically significant at the 5-percent-level, resulting in the equality of effects for treatments $A$ and $B$ being rejected $(\mathrm{p}=0.025)$. Note that these effect sizes on savings outcomes are similar to other recent interventions, but which operate with much higher intensity of instruction (e.g. Carpena et al., 2017; Calderone et al., 2018).

Components of the investment index. Turning to total investments into the own business, effect sizes are estimated to be 90,173 UGX for treatment A and 41,801 UGX for treatment B (column 4 in Table 4). Despite relatively large standard errors, the effect of treatment $\mathrm{A}$ is economically significant: The increase in investment by 90,173 UGX is equivalent to an increase by 30 percent relative to the control group. This corresponds to an effect size of 0.17 standard deviation units. The effect of treatment $\mathrm{B}$, again, is estimated to be less than half the size and statistically insignificant. The second component of the investment 
index looks at business formalization. The survey-data captures whether respondents report having formally registered the business with any authorities. Again, treatment A results in a statistically and economically significant effect, whereas treatment B yields effect sizes insignificant from zero: Given that only 23.2 percent of the control group state to have formally registered their business with authorities, an increase of 7.7 percentage points is sizeable (an increase in formalization of 33 percent) and significantly different from zero. In contrast, the effect of treatment $\mathrm{B}$, i.e. lecturing, is estimated to be insignificant from zero.

Outcomes on further items within indices. Even though the aggregate impact on the indices regarding the remaining outcome families is only marginally significant and insignificant, respectively (cf. Appendix A for a complete discussion of these results), we note results on single components here, since these qualitatively complement the general picture, that effect sizes of active learning are consistently estimated to be larger than effects of traditional lecturing.

The budgeting index consists of five binary items capturing changes in budgeting and record keeping behavior. Here, none of the items are impacted to a positive extent. Thus, the aggregate impact is insignificant from zero on average (see Table A4 in Appendix A).

The borrowing index consists of six items (see Table A5 in Appendix A). Items aggregated into this index capture the structure and volume of debt along with a proxy for debt-bearing capacity and binary items indicating whether respondents would take up loans without a plan or are able to distinguish between sensible and non-sensible reasons to take up a loan with interest payments. The coefficients on the volume of loans intended for consumption purposes and productive investments are extremely small and, thus, insignificant from zero. There is a significant effect for the active learning treatment, however, on the selfreport of respondents to take-up a loan (if offered) when they had no clear plan of how to use the money: approximately 14 percent of the control group report to be willing to take up a 
loan, even if they had no clear plan on how to use the borrowed amount. The marginal effect of the active learning treatment results in a 5.5 percentage point decrease in the willingness to take up a loan without a clear plan of its utilization. The effect of the traditional lecturing treatment, again, is insignificant from zero.

Finally, the financial service index includes two binary items indicating whether respondents were ever covered by a formal insurance product or if they have ever used mobile money (payment) services (cf. Jack and Suri, 2014; Suri and Jack, 2016) (see Table A6 in Appendix A). About 44 percent of the control group report having used mobile money services at least once and active learning has a marginal effect of 6.3 percentage points on mobile money use at the extensive margin. Lecturing, however, has a much smaller effect size (3.5 percentage points) and is statistically insignificant from zero. Both treatments have zeroeffects on formal insurance use.

\section{$5 \quad$ Exploring causal pathways}

The remarkable difference we uncover between the two versions of financial education intervention raises the question of potential causal mechanisms. Given that the financial education treatments are estimated to have zero impacts on incomes and days worked, the causal pathways from financial education to savings and investment outcomes warrant an investigation. Note, however, that these explorations were not pre-specified at the time of registration of the experiment. Thus, any analyses should be treated as exploratory. We motivate our procedure here (Section 5.1), then we introduce and discuss three kinds of potentially intermediating variables (Section 5.2), and finally we show exploratory results on potential causal pathways to behavior change (Section 5.3). 


\subsection{Potential mechanisms of financial education impact}

The early literature on the evaluation of financial education often focuses on the general effect size, because the existence of such a positive effect of financial education was heavily debated in the literature (cf. Fernandes et al., 2014). While many RCTs clearly demonstrate that there is a positive effect on both financial literacy and downstream financial behaviors, average effects are generally quite small in size and highly heterogeneous across studies. This raises interest in potential determinants of effective interventions: Meta-analyses find that education intensity matters for its impact and that the timing, participation conditions, and features of the target group can contribute to understanding the reported impact heterogeneity (cf. Fernandes et al., 2014; Miller et al., 2015; Kaiser and Menkhoff, 2017). However, little is known about how and why differently designed programs lead to heterogeneous impacts on financial behaviors. An important part of this discussion is to better understand the causal mechanisms by which financial education impacts behavior.

Regarding the psychological and economic content of such mechanisms, the first candidate is, of course, an improvement in financial literacy that enables individuals to make better financial decisions, i.e. financial education would impact financial behavior through a cognitive channel. Evidence on this possible causal pathway is documented (cf. Fort et al., 2016; Sayinzoga et al., 2016) and also appears to be supported by a larger sample of experimental work (see Kaiser and Menkhoff 2017, p.617). However, it is a robust insight of (financial) education research that a good transfer of knowledge into behavior is fostered by additional elements (cf. Carpena et al., 2011, 2017). Generally, in this respect, evidence shows that better self-control, and in line with it also future-oriented time-preferences, i.e. non-cognitive variables, seem to be associated with more savings (e.g. Ashraf et al., 2006). With regard to the literature on the causal effects of financial education, Lührmann et al. (2018) show that financial education can increase the quality of intertemporal decision- 
making. Similarly, Berg and Zia (2017) show that an intervention implemented into mainstream-media harnessing emotional connections also impacts financial behavior without necessarily impacting cognitive components of general financial literacy. Finally, financial confidence and attitudes may play an important role in financial behavior (e.g. Carpena et al., 2011; Berg and Zia, 2017). We explore these three main potential mechanisms, i.e. increased financial literacy, self-control, and financial confidence.

Regarding the empirical test of a causal pathway through these variables we follow recent work by Sayinzoga et al. (2016) and Bulte et al. (2017) by applying a two-stage estimation approach (see Section 2.3).

\subsection{Intermediating variables}

In the following we describe the formation of the three aforementioned variables. "Financial literacy" is assessed through five standard questions that are aggregated into a psychometrically valid scale of financial literacy (see Appendix C).

"Self-control" is assessed by a survey item asking respondents to reply to the question: "If you get money, do you tend to spend it too quickly?" on a 1 (often) to 4 (never) rating scale. Responses are transformed into a z-score, scaled by the mean and standard deviation for the control group (see descriptive statistics in Table 2 and in Table A7 in Appendix A).

"Financial confidence" is assessed by multiple items that are aggregated into an unweighted z-score-index of its components as detailed in Section 2.3. The index covers responses to binary questions and statements that are answered on a rating-scale. Questions were asked on whether or not respondents felt that a complaint to a financial services provider would not change anything, whether respondents feel confident to inquire about the details of a financial product and to choose the financial product that best meets their needs, and 
whether respondents consider various products and options before making a financial decision (see descriptive statistics and definitions in Table A7 in Appendix A).

\subsection{Results on causal pathways}

The results from applying the two-step estimation approach are presented in Table 5. In the two Panels A and B, we analyze one of the two indices of financial behavior where we find significant average treatment effects, as introduced above (see Section 4). Focusing first on the results of the first-stage regressions (which differ across the two panels because of different number of observations on outcomes), we find that the active learning treatment has significant effects on all three possible intermediating variables we consider: financial knowledge, self-control, and financial confidence. Treatment B, however, only affects financial confidence but neither our measure of financial knowledge nor our survey-measure of self-control. Thus, given that only treatment A has an effect on financial behavior and financial outcomes, we can conclude that changes in financial confidence alone (as is the case for treatment B) may not be sufficient to realize behavior change.

$<$ Table 5 about here>

Looking at the second-stage regressions, we see that improved savings behavior is mainly impacted via better self-control, while the investment index is impacted via improved financial literacy and financial confidence. Thus, all three intermediating variables may play a role, however, in different ways: the nexus between self-control and savings confirms earlier studies, and investment outcomes are mainly affected by literacy and confidence, confirming the results on the literature of business training interventions. We note that treatment A, i.e. the active learning approach, seems to activate all three mechanisms and all of them may be supportive in changing financial behavior. 


\section{Treatment effect heterogeneity}

This section investigates potentially heterogeneous effects from treatment by an examination of how treatment effects may be conditional on levels of outcomes (Section 6.1) and how treatment effects may interact with observable traits of the target group (Section 6.2).

\subsection{Distributional treatment effects}

Indeed, simultaneous quantile regressions show that the advantageous effects of the financial education training are heterogeneous. Note that the following interpretations make the implicit assumption of rank invariance. Starting with the financial literacy index, the effect of treatment A (active learning) is largely independent from the outcome level of financial literacy (see Table 6, column 1). Graphically speaking, the entire distribution of knowledge levels appears to be shifted to the right in response to the active learning treatment. By contrast, the effect of treatment B (traditional lecturing) is quite strong only below the median (although not much stronger than that of treatment A) while coefficients are about zero above the median. These differential effects become especially apparent at the top of the financial literacy distribution $(\mathrm{p}<0.1)$. We conclude that treatment $\mathrm{B}$ may be an alternative approach in this respect if only individuals with very low levels of financial literacy belong to the target group, i.e. for individuals who may never have been confronted with any of the contents of the training. Active learning, however, appears to be beneficial across the entire range of the financial literacy distribution.

<Table 6 about here>

Regarding the outcome level of the savings index, treatment A has clearly larger and significant effects above the median, while effects of treatment $\mathrm{B}$ are very small and insignificant across the whole distribution. Thus, differential treatment effects of active learning within the savings domain are driven by relatively large effects in the $60^{\text {th }}$ and $80^{\text {th }}$ 
percentile, while effect sizes are small below the median. This would indicate that financial education may increase savings-inequality with respect to our target group which is consistent with a recent theoretical model of endogenous financial knowledge and wealth inequality (Lusardi et al., 2017).

A similar pattern arises with respect to the investment index, although at a higher level of effect sizes. Treatment A has significant effects from the $40^{\text {th }}$ percentile upwards. Again, effect sizes are largest at the top of the outcome distribution. In addition, treatment B also appears to generate the intended effects at some points of the outcome distribution, being significant at the median and at the $60^{\text {th }}$ percentile, but always with smaller estimated effect sizes and overall insignificant average impact.

Overall, we draw two conclusions: first, active learning seems to be effective in increasing financial literacy scores across the entire distribution; and second, regarding the savings and the investment index, effects are largest for those individuals with higher levels of outcomes and zero for people at the bottom of the outcome distributions for savings and investing. Thus, financial education may not be beneficial for the most constrained individuals in our sample, confirming the intuition that investments in financial knowledge may not be rational and beneficial for all individuals (cf. Lusardi et al., 2017).

\subsection{Subgroup analyses}

Turning to an investigation of treatment effects by subgroups along observable characteristics of the respondents, we examine the possibility of heterogeneous treatment effects for three subgroups that generally are known to have different levels of ex-ante financial literacy and may respond differently to financial education programs (cf. Lusardi and Mitchell, 2014). First, gender differences are treated as a stylized fact in the literature, with men scoring higher on financial knowledge tests than women in most surveys. Second, 
financial literacy is correlated with general educational attainment. In our sample, nearly 32 percent cannot read or write in any language and only and 25.35 percent have more than primary education. Thus, differential impacts conditional on general educational attainment may occur. Third, we examine differential impacts conditional on baseline financial literacy levels.

The three panels of Table 7 show an investigation of heterogeneous treatment effects for the subgroups discussed above. In each panel, binary indicators for each group are interacted with the treatment dummies to estimate the heterogeneous effects. The results are mixed:

$<$ Table 7 about here>

Starting with the impact on financial literacy scores (column 1), it can be observed that treatment effects of treatment A appear to be heterogeneous only with respect to gender. First, the positive treatment effect on financial literacy may be driven predominately by a very strong treatment effect on males' financial literacy scores whereas the treatment effect for females appears to be small and insignificant (Panel $A$ ). Considering the other indicators, no significant interactions appear to exist (Panels $B$ and $C$ ).

Turning to outcomes with regard to financial behaviors, however, indicates that treatment effects appear to be less heterogeneous and the average positive treatment effects discussed above are still present when investigating effects for subgroups.

Apart from strong negative interaction effects of the male indicator with the dummy for treatment B (suggesting males respond negatively to this treatment leading to worse outcomes on the debt index but), none of the interactions appear to be statistically significant and meaningful. One exception may be that those who have above average financial literacy scores at baseline appear to respond more positively to the treatments with respect to budgeting behavior, i.e. respondents may only be able to translate the benefits of the training 
into action (e.g. creating a written household budget) if they are relatively knowledgeable at baseline.

Interestingly, impacts on downstream financial behaviors, such as savings and investments, are not conditional on prior skill-levels (education or financial literacy). This is in contrast to other experiments: Bjorvatn and Tungodden (2010) report that business training in Tanzania is most effective for low-skilled individuals. Drexler et al. (2014) show that benefits of "rules of thumb" training are especially driven by large impacts on low-skilled respondents (cf. Drexler et al., 2014, p.25). Finally, Fort et al. (2016) document that exogenous variation in bank information policies impacts financial literacy and financial behavior, with effects highest for low-educated elderly households. Benefits of active learning, however, appear to be universal for our sample and generally not contingent on lowability.

\section{$7 \quad$ Robustness}

We demonstrate in robustness checks that results of the main paper are robust. These checks are briefly reported here, while details are provided in Appendix B, and cover three main areas: (i) As the sample is characterized by mild attrition, we carefully address this issue showing that there is no reason for concern, among others, by inverse probability weighting for selection into endline survey and bounds analysis testing results under several scenarios; (ii) we show OLS-results using only endline data; and finally, (iii) while the measure of financial literacy used here has better psychometric properties than simple unweighted sumscores of standard items, we show that also a more common measure of sumscores leads to a qualitatively identical result. 


\section{Conclusion}

Our research contributes to revealing the determinants of successful financial education. As a potentially crucial determinant of effective financial education, we compare an active learning approach with traditional lecturing. Active learning is shown to be clearly superior in the field of science education, thus providing strong motivation to test the approach in financial education.

The main result is clear cut: We study five outcome groups of financial behavior, such as savings and investments, finding that active learning outperforms traditional lecturing. In three out of five cases, active learning has the intended effect on financial behavior to a significant degree, while traditional lecturing never has a significant effect. Coefficients of active learning tend to be clearly larger, although the differential treatment effects compared to lecturing are only significant for the savings domain and for a single item in the debt index. Still, given the relatively limited power of our cluster-RCT, with 1,162 vendors in the endline survey and a short educational intervention of only 120 minutes, the advantage of active learning seems quite strong. Thus, one explanation for the muted effects of classroom programs observed in the present literature may lie in the form of exposition centered instructional design that falls short of translating financial knowledge into financial behavior.

In a second step, we aim to better understand the mechanisms intermediating financial education into changes in financial behavior. For this purpose, we examine the role of financial literacy, self-control, and financial confidence separately by applying a two-stage estimation in line with Sayinzoga et al. (2016) and Bulte et al. (2017), where the intermediating variables are instrumented by the financial education treatments. We find that active learning has a positive impact on all three considered intermediating variables, while lecturing only impacts financial confidence. Moreover, we reveal that financial outcomes seem to be impacted by changes in specific intermediating variables, suggesting that the 
transfer from education to a change in behavior differs depending upon the kind of behavior. This would call for financial education that is not only specific to target groups (cf. Gibson et al., 2014; Doi et al., 2016) but also to the outcome variables.

Last, we document that benefits from active learning are not conditional on the human capital of participants but may be ineffective for the financially most constrained individuals. Overall, active learning methods may be an effective way to improve existing classroom programs without increasing the costs that result from other approaches, such as lowering the student to teacher ratio or moving to strictly personalized interventions such as counseling. An important area for future research may be to study the effects of active learning over a longer time horizon and to extend our research and apply the approach to a broader set of target groups. 


\section{References}

Ashraf, N., Karlan, D., and Yin, W. (2006). Tying Odysseus to the mast: Evidence from a commitment savings product in the Philippines. Quarterly Journal of Economics, 121(2): $635-672$.

Berg, G. and Zia, B. (2017). Harnessing emotional connections to improve financial decisions. Evaluating the impact of financial education in mainstream media. Journal of the European Economic Association, 15(5): 1025-1055.

Bjorvatn, K, and Tungodden, B. (2010). Teaching business in Tanzania: Evaluating participation and performance. Journal of the European Economic Association, 8(2-3): 561570 .

Blattman, C., Fiala, N., and Martinez, S. (2014). Generating skilled self-employment in developing countries: Experimental evidence from Uganda. Quarterly Journal of Economics, 129(2): 697-752.

Bruhn, M., Ibarra, G.L., and McKenzie, D. (2014). The minimal impact of a large-scale financial education program in Mexico City. Journal of Development Economics, 108: 184189.

Bruhn, M., de Souza Leao, L., Legovini, A., Marchetti, R., and Zia, B. (2016). The impact of high school financial education: Evidence from a large-scale evaluation in Brazil. American Economic Journal: Applied Economics, 8(4): 256-95.

Brown, M., Grigsby, J., van der Klaauw, W., Wen, J., and Zafar, B. (2016). Financial education and the debt behavior of the young. Review of Financial Studies, 29(9): 2490-2522.

Bulte, E., Lensink, R., and Vu, N. (2017). Do gender and business trainings affect business outcomes? Experimental evidence from Vietnam. Management Science, 63(9): 2885-2902.

Calderone, M., Fiala, N., Mulaj, F. Sadhu, S., and Sarr, L. (2018). Financial education and savings behavior: Evidence from a randomized experiment among low income clients of branchless banking in India. Economic Development and Cultural Change, forthcoming.

Campos, F., Frese, M., Goldstein, M., Iacovone, L., Johnson, H. C., McKenzie, D., and Mensmann, M. (2017). Teaching personal initiative beats traditional training in boosting small business in West Africa. Science, 357(6357): 1287-1290.

Carpena, F., Cole, S., Shapiro, J., and Zia, B. (2011). Unpacking the causal chain of financial literacy. World Bank Policy Research Working Paper, No. 5798.

Carpena, F., Cole, S., Shapiro, J., and Zia, B. (2017). The ABCs of financial education. Experimental evidence on attitudes, behavior, and cognitive biases. Management Science https://doi.org/10.1287/mnsc.2017.2819.

Cole, S., Sampson, T., and Zia, B. (2011). Prices or knowledge? What drives demand for financial services in emerging markets? Journal of Finance, 66(6): 1933-1967.

Cole, S., Gine, X., Tobacman, J., Topalova, P., Townsend, R., and Vickery, J. (2013). Barriers to household risk management: Evidence from India. American Economic Journal: Applied Economics, 5(1): 104-135. 
Cole, S., Paulson, A., and Shastry, G.K. (2016). High school curriculum and financial outcomes: The impact of mandated personal finance and mathematics courses. Journal of Human Resources, 51(3): 656-698.

De Mel, S., McKenzie, D., and Woodruff, C. (2011). Getting credit to high return microentrepreneurs: The results of an information intervention. World Bank Economic Review, 25(3): 456-485.

Deslauriers, L., Schelew, E., and Wieman, C. (2011). Improved learning in a large-enrollment physics class. Science, 332(6031): 862-864.

Doi, Y., McKenzie, D., and Zia, B. (2014). Who you train matters: Identifying combined effects of financial education on migrant households. Journal of Development Economics, 109: 39-55.

Drexler, A., Fischer, G., and Schoar, A. (2014). Keeping it simple: Financial literacy and rules of thumb. American Economic Journal: Applied Economics, 6(2): 1-31.

Duflo, E. and Saez, E. (2003). The role of information and social interactions in retirement plan decisions: Evidence from a randomized experiment. Quarterly Journal of Economics, 118(3): 815-842.

Fernandes, D., Lynch Jr., J.G., and Netemeyer, R.G. (2014). Financial literacy, financial education, and downstream financial behaviors. Management Science, 60(8): 1861-1883.

Fort, M., Manaresi, F., and Trucchi, S. (2016). Adult financial literacy and households' financial assets: The role of bank information policies. Economic Policy, 31(88): 743-782.

Freeman, S., Eddy, S.L., McDonough, M., Smith, M.K., Okoroafor, N., Jordt, H., and Wenderoth, M.P. (2014). Active learning increases student performance in science, engineering, and mathematics. Proceedings of the National Academy of Sciences, 111(23): 8410-8415.

Gibson, J., McKenzie, D., and Zia, B. (2014). The impact of financial literacy training for migrants. World Bank Economic Review, 28(1): 130-161.

Hastings, J.S., Madrian, B.C., and Skimmyhorn, W.L. (2013). Financial literacy, financial education, and economic outcomes. Annual Review of Economics, 5: 347-373.

Jack, W., and Suri, T. (2014). Risk sharing and transactions costs: Evidence from Kenya's mobile money revolution. American Economic Review, 104(1): 183-223.

Jamison, J.C., Karlan, D, and Zinman, J. (2014). Financial education and access to savings accounts: Complements or substitutes? Evidence from Ugandan youth clubs. NBER Working Paper 20135.

Kaiser, T. and Menkhoff, L. (2017). Does financial education impact financial behavior, and if so, when? World Bank Economic Review, 31(3): 611-630.

Karlan, D. and Valdivia, M. (2011). Teaching entrepreneurship: Impact of business training on microfinance clients and institutions. Review of Economics and Statistics, 93(2): 510-527.

Kling, J.R., Liebman, J.B., and Katz, L.F. (2007). Experimental analysis of neighborhood effects. Econometrica, 75(1): 83-119. 
Lusardi, A. and Mitchell, O. S. (2014). The economic importance of financial literacy: Theory and evidence. Journal of Economic Literature, 52(1): 5-44.

Lusardi, A., Michaud, P.-C., and Mitchell, O.S. (2017). Optimal financial knowledge and wealth inequality. Journal of Political Economy, 125(2): 431-477.

Lusardi, A., Samek, A.S., Kapteyn, A., Glinert, L., Hung, A., and Heinberg, A. (2017). Visual tools and narratives: New ways to improve financial literacy. Journal of Pension Economics and Finance, 16(3): 297-323.

Lührmann, M., Serra-Garcia, M., and Winter, J. (2018). The impact of financial education on adolescents' intertemporal choices. American Economic Journal: Economic Policy, forthcoming.

McKenzie, D. (2012). Beyond baseline and follow-up: The case for more $\mathrm{T}$ in experiments. Journal of Development Economics, 99(2): 210-221.

Miller, M., Reichelstein, J., Salas, C., and Zia, B. (2015). Can you help someone become financially capable? A meta-analysis of the literature. World Bank Research Observer, 30(2): 220-246.

Muller, S.M. (2015). Causal interaction and external validity: Obstacles to the policy relevance of randomized evaluations. World Bank Economic Review, 29: S217-S225.

Ruiz-Primo, M.A., Briggs, D., Iverson, H., Talbot, R., and Shepard, L.A. (2011). Impact of undergraduate science course innovations on learning. Science, 331(6022): 1269-1270.

Sayinzoga, A., Bulte, E.H., and Lensink, R. (2016). Financial literacy and financial behaviour: Experimental evidence from rural Rwanda. Economic Journal, 126(594): 15711599.

Skimmyhorn, W. (2016). Assessing financial education: Evidence from boot camp. American Economic Journal: Economic Policy, 8(2): 322-343.

Skimmyhorn, W.L., Davies, E.R., Mun, D., and Mitchell, B. (2016). Assessing financial education methods: Principles vs. rules-of-thumb approaches. Journal of Economic Education, 47(3): 193-210.

Suri, T. and Jack, W. (2016). The long-run poverty and gender impacts of mobile money. Science, 354(6317): 1288-1292.

van Rooij, M., Lusardi, A., and Alessie, R. (2011). Financial literacy and stock market participation. Journal of Financial Economics 101(2): 449-72.

Wieman, C. E. (2014). Large-scale comparison of science teaching methods sends clear message. Proceedings of the National Academy of Sciences, 111(23): 8319-8320. 
Figure 1: Location and treatment status of 83 clusters

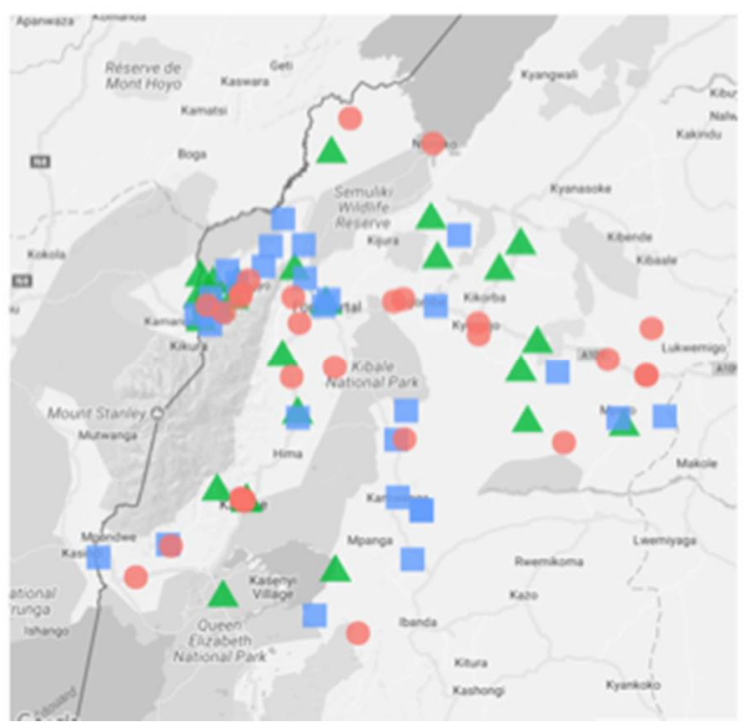

\section{Control group}

Treatment A: Active learning

Treatment B: Traditional lecturing

Table 1: Sample overview and response-rates

\begin{tabular}{|c|c|c|c|c|c|}
\hline & \multirow[t]{2}{*}{$\underline{\text { Wave }}$} & \multirow[t]{2}{*}{ Control group } & \multicolumn{2}{|c|}{$\underline{\text { Treatment groups }}$} & \multirow[t]{2}{*}{$\underline{\text { Total }}$} \\
\hline & & & Treatment A & Treatment B & \\
\hline \multirow{2}{*}{$\begin{array}{l}\text { Clusters } \\
\text { (marketplaces) } \\
(\%)\end{array}$} & Baseline & $\begin{array}{l}28 \\
(33.73 \%)\end{array}$ & $\begin{array}{l}27 \\
(32.54 \%)\end{array}$ & $\begin{array}{l}28 \\
(33.73 \%)\end{array}$ & $\begin{array}{l}83 \\
(100 \%)\end{array}$ \\
\hline & Endline & $\begin{array}{l}28 \\
(33.73 \%)\end{array}$ & $\begin{array}{l}27 \\
(32.54 \%)\end{array}$ & $\begin{array}{l}28 \\
(33.73 \%)\end{array}$ & $\begin{array}{l}83 \\
(100 \%)\end{array}$ \\
\hline \multirow[t]{3}{*}{$\begin{array}{l}\text { Individuals } \\
(\%)\end{array}$} & Baseline & $\begin{array}{l}456 \\
(35.32 \%)\end{array}$ & $\begin{array}{l}414 \\
(32.07 \%)\end{array}$ & $\begin{array}{l}421 \\
(32.61 \%)\end{array}$ & $\begin{array}{l}1,291 \\
(100 \%)\end{array}$ \\
\hline & Endline & $\begin{array}{l}417 \\
(35.89 \%)\end{array}$ & $\begin{array}{l}384 \\
(33.05 \%)\end{array}$ & $\begin{array}{l}361 \\
(31.06 \%)\end{array}$ & $\begin{array}{l}1,162 \\
(100 \%)\end{array}$ \\
\hline & $\begin{array}{l}\text { Attrition } \\
\text { (individuals) }\end{array}$ & $\begin{array}{l}39 \\
(8.55 \%)\end{array}$ & $\begin{array}{l}30 \\
(7.25 \%)\end{array}$ & $\begin{array}{l}60 \\
(14.25 \%)\end{array}$ & $\begin{array}{l}129 \\
(9.99 \%)\end{array}$ \\
\hline
\end{tabular}

Notes: Randomization was done in Stata and is fully reproducible. The cluster-level dataset contained one duplicate cluster (market) that was known by two different names in the local languages. Thus, randomization was done with 84 markets. This was discovered only after randomization and initial field activities. The duplicate (which was allocated to group A) was removed ex post. The baseline survey was conducted between November $2^{\text {nd }}$ and December $19^{\text {th }}, 2015$. The follow-up survey was conducted between April $6^{\text {th }}$ and July $19^{\text {th }}$ of 2016 with additional tracking efforts and surveys in October 2016 and February 2017 (see Timeline Figure A1 in Appendix A). 
Table 2: Summary statistics and randomization-balance at baseline

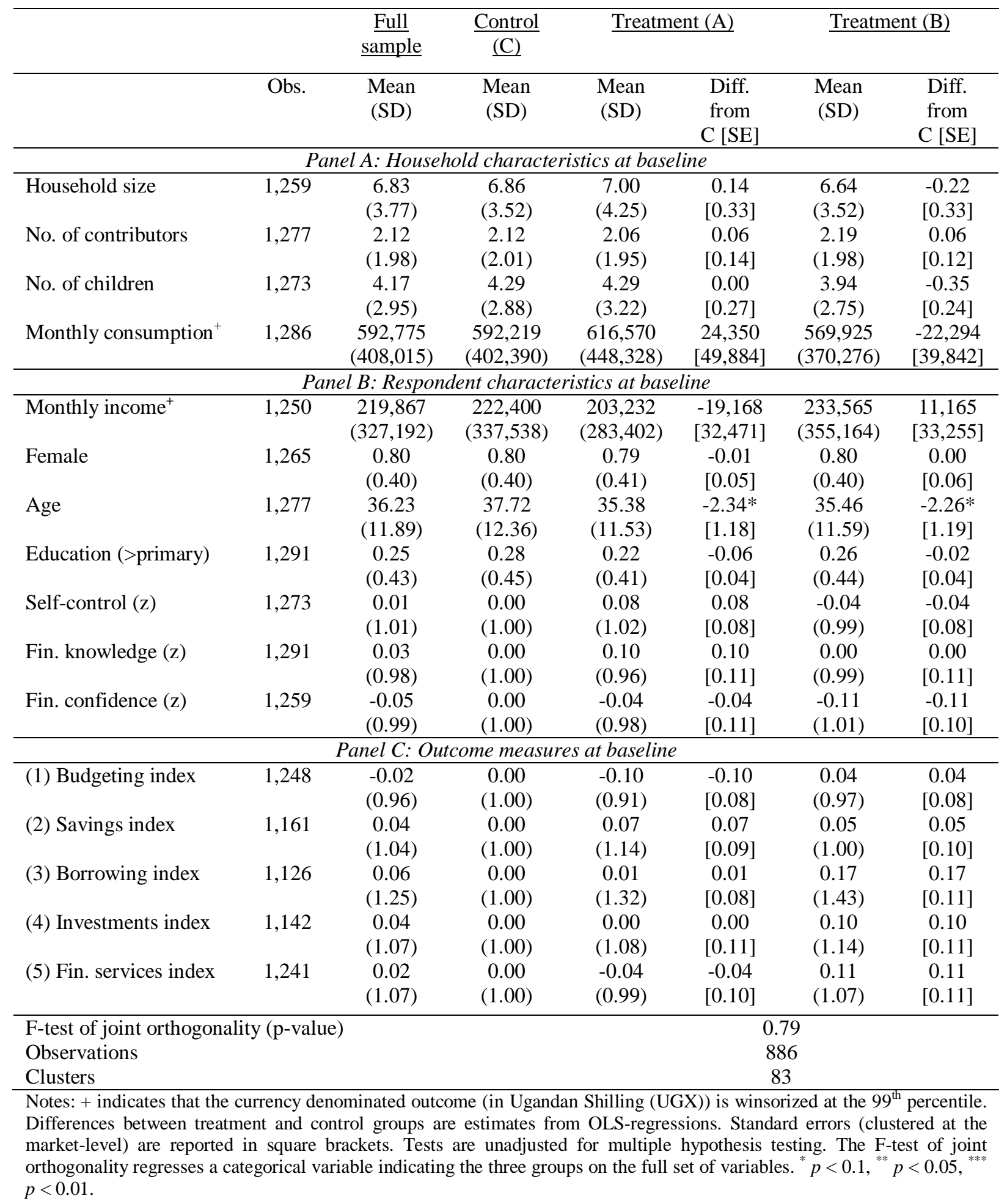


Table 3: Main experimental results (ANCOVA)

\begin{tabular}{|c|c|c|c|c|c|}
\hline & $\begin{array}{c}\text { (1) } \\
\text { Budgeting } \\
\text { index }(\mathrm{z})\end{array}$ & $\begin{array}{c}(2) \\
\text { Savings } \\
\text { index }(z)\end{array}$ & $\begin{array}{c}(3) \\
\text { Debt } \\
\text { index }(z)\end{array}$ & $\begin{array}{c}(4) \\
\text { Investment } \\
\text { index }(\mathrm{z}) \\
\end{array}$ & $\begin{array}{c}(5) \\
\text { Fin. services } \\
\text { index }(\mathrm{z})\end{array}$ \\
\hline \multirow[t]{2}{*}{ Treatment A } & 0.045 & $0.164 * *$ & $0.106^{*}$ & $0.284 * * *$ & 0.109 \\
\hline & $(0.087)$ & $(0.071)$ & $(0.057)$ & $(0.097)$ & $(0.077)$ \\
\hline \multirow[t]{2}{*}{ Treatment B } & 0.009 & 0.013 & -0.037 & 0.168 & 0.149 \\
\hline & $(0.088)$ & $(0.077)$ & $(0.075)$ & $(0.119)$ & $(0.095)$ \\
\hline$A-B=0$ (p-value) & 0.690 & $0.077^{*}$ & $0.051^{*}$ & 0.353 & 0.678 \\
\hline $\mathrm{R}^{2}$ & 0.108 & 0.152 & 0.009 & 0.144 & 0.130 \\
\hline Mean $(\mathrm{SD})$ of $y_{t}$ in & 0.000 & 0.000 & 0.000 & 0.000 & 0.000 \\
\hline control group & $(1.000)$ & $(1.000)$ & $(1.000)$ & $(1.000)$ & $(1.000)$ \\
\hline Observations & 1,114 & 1,161 & 1,108 & 1,007 & 1,136 \\
\hline Clusters & 83 & 83 & 83 & 83 & 83 \\
\hline District FEs & yes & Yes & yes & yes & yes \\
\hline$y_{(t-1)}$ covariate & yes & Yes & yes & yes & yes \\
\hline
\end{tabular}

Notes: Table shows OLS regression results of ANCOVA models. The dependent variables $\left(y_{t}\right)$ are equally weighted z-score indices of financial behavior and are standardized to have a zero mean and a standard deviation of one for the control group. Thus, coefficients can be interpreted as effect sizes (Glass's $\Delta$ ). All currency denominated outcomes (in Ugandan Shilling (UGX)) within the indices in columns (2), (3) and (4) are winsorized at the $99^{\text {th }}$ percentile. All models include the lagged outcome at baseline and district-level fixed effects. Standard errors (clustered at the market-level) are reported in parentheses. ${ }^{*} p<0.1,{ }^{* *} p<0.05,{ }^{* * *} p<0.01$.

Table 4: Analysis of individual index components saving and investing

\begin{tabular}{|c|c|c|c|c|c|}
\hline & \multicolumn{3}{|c|}{ (a) Savings index } & \multicolumn{2}{|c|}{ (b) Investment index } \\
\hline & $\begin{array}{c}\text { (1) } \\
\text { Any savings }\end{array}$ & $\begin{array}{c}(2) \\
\text { Total savings } \\
\end{array}$ & $\begin{array}{c}(3) \\
\text { Net } \\
\text { savings }^{+}\end{array}$ & $\begin{array}{c}\text { (4) } \\
\text { Total } \\
\text { investments }^{+}\end{array}$ & $\begin{array}{l}\text { (5) } \\
\text { Business } \\
\text { formally } \\
\text { registered }\end{array}$ \\
\hline Treatment A & $\begin{array}{l}0.038^{*} \\
(0.020)\end{array}$ & $\begin{array}{l}109,186 * \\
(65,132)\end{array}$ & $\begin{array}{c}145,480 * * \\
(64,784)\end{array}$ & $\begin{array}{l}90,173^{*} \\
(47,461)\end{array}$ & $\begin{array}{l}0.077 * * \\
(0.034)\end{array}$ \\
\hline Treatment B & $\begin{array}{c}0.027 \\
(0.023)\end{array}$ & $\begin{array}{l}-32,519 \\
(68,588)\end{array}$ & $\begin{array}{l}-14,226 \\
(66,476)\end{array}$ & $\begin{array}{c}41,801 \\
(63,124)\end{array}$ & $\begin{array}{c}0.060 \\
(0.037)\end{array}$ \\
\hline$A-B=0$ (p-value) & 0.601 & $0.052 *$ & $0.025^{* *}$ & 0.487 & 0.640 \\
\hline $\mathrm{R}^{2}$ & 0.024 & 0.244 & 0.131 & 0.184 & 0.035 \\
\hline $\begin{array}{l}\text { Mean (SD) of } y_{t} \text { in } \\
\text { control group }\end{array}$ & $\begin{array}{c}0.878 \\
(0.328)\end{array}$ & $\begin{array}{c}513,629 \\
(937,119)\end{array}$ & $\begin{array}{c}380,568 \\
(973,769)\end{array}$ & $\begin{array}{c}301,067 \\
(526,957)\end{array}$ & $\begin{array}{c}0.232 \\
(0.423)\end{array}$ \\
\hline Observations & 1,161 & 1,162 & 1,162 & 1,053 & 1,110 \\
\hline Clusters & 83 & 83 & 83 & 83 & 83 \\
\hline District FEs & yes & yes & yes & yes & yes \\
\hline$y_{(t-1)}$ covariate & yes & yes & yes & yes & yes \\
\hline
\end{tabular}


Table 5: 2SLS-regressions to probe the causal mechanisms from financial education to savings outcomes

\begin{tabular}{|c|c|c|c|c|c|c|}
\hline & \multicolumn{3}{|c|}{$1^{\text {st }}$ stage } & \multicolumn{3}{|c|}{$2^{\text {nd }}$ stage } \\
\hline & \multicolumn{6}{|c|}{ Panel A: Savings outcomes } \\
\hline & $\begin{array}{c}\text { (1) } \\
\text { Fin. } \\
\text { literacy }\end{array}$ & $\begin{array}{c}\text { (2) } \\
\text { Self-control }\end{array}$ & $\begin{array}{c}\text { (3) } \\
\text { Fin. } \\
\text { confidence }\end{array}$ & $\begin{array}{c}(4) \\
\text { Savings } \\
\text { index }(z)\end{array}$ & $\begin{array}{c}(5) \\
\text { Savings } \\
\text { index }(z)\end{array}$ & $\begin{array}{c}(6) \\
\text { Savings } \\
\text { index }(z)\end{array}$ \\
\hline Treatment A & $\begin{array}{l}0.152^{*} \\
(0.086)\end{array}$ & $\begin{array}{l}0.152^{*} \\
(0.079)\end{array}$ & $\begin{array}{c}0.160 * * \\
(0.081)\end{array}$ & & & \\
\hline Treatment B & $\begin{array}{c}0.076 \\
(0.076)\end{array}$ & $\begin{array}{l}-0.058 \\
(0.092)\end{array}$ & $\begin{array}{c}0.193 * * \\
(0.083)\end{array}$ & & & \\
\hline Fin. literacy* & & & & $\begin{array}{c}1.320 \\
(0.880)\end{array}$ & & \\
\hline Self-control* & & & & & $\begin{array}{l}0.864 * \\
(0.524)\end{array}$ & \\
\hline Fin. confidence $*$ & & & & & & $\begin{array}{c}0.536 \\
(0.480)\end{array}$ \\
\hline \multirow[t]{3}{*}{ Observations } & 1,162 & 1,156 & 1,026 & 1,162 & 1,157 & 1,027 \\
\hline & \multicolumn{6}{|c|}{ Panel B: Investment outcomes } \\
\hline & $\begin{array}{c}\text { Fin. } \\
\text { literacy }\end{array}$ & Self-control & $\begin{array}{c}\text { Fin. } \\
\text { confidence }\end{array}$ & $\begin{array}{l}\text { Investment } \\
\text { index (z) }\end{array}$ & $\begin{array}{l}\text { Investment } \\
\text { index (z) }\end{array}$ & $\begin{array}{c}\text { Investment } \\
\text { index (z) }\end{array}$ \\
\hline Treatment A & $\begin{array}{c}0.188 * * \\
(0.094)\end{array}$ & $\begin{array}{c}0.134 \\
(0.086)\end{array}$ & $\begin{array}{l}0.141 * \\
(0.079)\end{array}$ & & & \\
\hline Treatment B & $\begin{array}{c}0.098 \\
(0.083)\end{array}$ & $\begin{array}{l}-0.073 \\
(0.093)\end{array}$ & $\begin{array}{c}0.217 * * * \\
(0.074)\end{array}$ & & & \\
\hline Fin. literacy* & & & & $\begin{array}{l}1.683 * \\
(0.955)\end{array}$ & & \\
\hline Self-control* & & & & & $\begin{array}{c}0.734 \\
(0.660)\end{array}$ & \\
\hline Fin. confidence* & & & & & & $\begin{array}{l}1.321 * \\
(0.742)\end{array}$ \\
\hline Observations & 1,037 & 1,033 & 920 & 1,037 & 1,033 & 920 \\
\hline Clusters & 83 & 83 & 83 & 83 & 83 & 83 \\
\hline District FEs & yes & yes & yes & yes & yes & yes \\
\hline$y_{(t-1)}$ covariate & no & no & no & no & no & no \\
\hline
\end{tabular}

Notes: Results show two stage regressions. All models district-level fixed effects. Standard errors (clustered at the marketlevel) in parentheses. ${ }^{*} p<0.1,{ }^{* *} p<0.05,{ }^{* * *} p<0.01$. 
Table 6: Simultaneous-quantile regressions for indices of financial knowledge, savings, and investment

\begin{tabular}{|c|c|c|c|c|}
\hline & & $\begin{array}{c}(1) \\
\text { Fin. } \\
\text { literacy }(\mathrm{z})\end{array}$ & $\begin{array}{c}(2) \\
\text { Savings } \\
\text { index (z) }\end{array}$ & $\begin{array}{c}(3) \\
\text { Investment } \\
\text { index }(\mathrm{z})\end{array}$ \\
\hline \multirow[t]{4}{*}{$20^{\text {th }}$ percentile } & Treatment A & $\begin{array}{c}0.161 \\
(0119)\end{array}$ & $\begin{array}{c}0.038 \\
(0.032)\end{array}$ & $\begin{array}{c}0.027 \\
(0.017)\end{array}$ \\
\hline & Treatment B & $0.281 * *$ & 0.017 & 0.015 \\
\hline & & $(0.120)$ & $(0.034)$ & $(0.020)$ \\
\hline & $A-B=0(\mathrm{p}$-value $)$ & 0.372 & 0.412 & 0.560 \\
\hline \multirow[t]{5}{*}{$40^{\text {th }}$ percentile } & Treatment A & $0.180^{*}$ & 0.027 & $0.095 * *$ \\
\hline & & $(0.109)$ & $(0.020)$ & $(0.042)$ \\
\hline & Treatment B & $0.204^{*}$ & -0.001 & 0.044 \\
\hline & & $(0.108)$ & $(0.020)$ & $(0.035)$ \\
\hline & $A-B=0$ (p-value $)$ & 0.804 & 0.210 & 0.315 \\
\hline \multirow[t]{5}{*}{ Median } & Treatment A & 0.108 & 0.037 & $0.155^{* *}$ \\
\hline & & $(0.111)$ & $(0.027)$ & $(0.0649)$ \\
\hline & Treatment B & 0.101 & -0.003 & $0.108 * *$ \\
\hline & & $(0.096)$ & $(0.027)$ & $(0.055)$ \\
\hline & $A-B=0(\mathrm{p}$-value $)$ & 0.941 & 0.177 & 0.527 \\
\hline \multirow[t]{5}{*}{$60^{\text {th }}$ percentile } & Treatment A & 0.154 & $0.068 * *$ & $0.301 * *$ \\
\hline & & $(0.135)$ & $(0.029)$ & $(0.143)$ \\
\hline & Treatment B & -0.022 & 0.007 & $0.137 *$ \\
\hline & & $(0.115)$ & $(0.029)$ & $(0.076)$ \\
\hline & $A-B=0$ (p-value $)$ & 0.154 & $0.064 *$ & 0.263 \\
\hline \multirow{5}{*}{$80^{\text {th }}$ percentile } & Treatment A & 0.136 & $0.137^{*}$ & $0.466^{* *}$ \\
\hline & & $(0.095)$ & $(0.072)$ & $(0.208)$ \\
\hline & Treatment B & -0.037 & -0.037 & 0.187 \\
\hline & & $(0.096)$ & $(0.057)$ & $(0.206)$ \\
\hline & $A-B=0$ (p-value $)$ & $0.091 *$ & $0.021 * *$ & 0.162 \\
\hline Observations & & 1,162 & 1,161 & 1,007 \\
\hline Clusters & & 83 & 83 & 83 \\
\hline District FEs & & yes & yes & yes \\
\hline$y_{(t-1)}$ covariate & & yes & yes & yes \\
\hline Mean $(\mathrm{SD})$ of $y_{t}$ in & & 0.000 & 0.000 & 0.000 \\
\hline control group & & $(1.000)$ & $(1.000)$ & $(1.000)$ \\
\hline
\end{tabular}

Notes: Results present simultaneous-quantile regressions for the impact of the financial education treatments $\mathrm{A}$ and $\mathrm{B}$ on indices of financial knowledge (1), savings (2), and investments (3). The dependent variables are equally weighted z-score indices of their respective components as discussed in Section 2.4 and are standardized to have a zero mean and a standard deviation of one for the control group. Thus, coefficients can be interpreted as effect sizes (Glass's $\Delta$ ). The output presents treatment effects for each quartile and the median. All currency denominated outcomes (in Ugandan Shilling (UGX)) within the indices in columns (2) and (3) are winsorized at the $99^{\text {th }}$ percentile. All models include the lagged outcome at baseline and district-level fixed effects. Standard errors in parentheses are bootstrapped with 1,000 replications. ${ }^{*} p<0.1,{ }^{* * *} p<0.05$, $p<0.01$. 
Table 7: Heterogeneous treatment effects for subgroups

\begin{tabular}{|c|c|c|c|c|c|c|}
\hline & $\begin{array}{c}1) \\
\text { FL } \\
\text { score }(z)\end{array}$ & $\begin{array}{c}(2) \\
\text { Budgeting } \\
\text { index }(\mathrm{z})\end{array}$ & $\begin{array}{c}(3) \\
\text { Savings } \\
\text { index }(\mathrm{z})\end{array}$ & $\begin{array}{c}(4) \\
\text { Debt } \\
\text { index }(z)\end{array}$ & $\begin{array}{c}(5) \\
\text { Investment } \\
\text { index }(\mathrm{z})\end{array}$ & $\begin{array}{c}(6) \\
\text { Fin. services } \\
\text { index }(\mathrm{z})\end{array}$ \\
\hline \multicolumn{7}{|c|}{ Panel A: Male respondents } \\
\hline \multirow[t]{2}{*}{ Treatment A } & 0.053 & 0.029 & $0.186^{* *}$ & $0.141 * *$ & $0.224 * *$ & 0.062 \\
\hline & $(0.100)$ & $(0.085)$ & $(0.075)$ & $(0.065)$ & $(0.0863)$ & $(0.077)$ \\
\hline \multirow[t]{2}{*}{ Treatment B } & 0.044 & 0.001 & 0.042 & 0.0470 & 0.168 & $0.168 *$ \\
\hline & $(0.086)$ & $(0.089)$ & $(0.072)$ & $(0.088)$ & $(0.106)$ & $(0.091)$ \\
\hline \multirow[t]{2}{*}{ Male } & -0.101 & $0.307 * *$ & $0.307 * *$ & $0.407 * * *$ & $0.406 * *$ & $0.362 * * *$ \\
\hline & $(0.101)$ & $(0.147)$ & $(0.125)$ & $(0.122)$ & $(0.172)$ & $(0.109)$ \\
\hline \multirow[t]{2}{*}{ Treatment $\mathrm{A} \times$ Male } & $0.392 * *$ & 0.079 & -0.047 & -0.205 & 0.274 & 0.157 \\
\hline & $(0.170)$ & $(0.214)$ & $(0.204)$ & $(0.185)$ & $(0.348)$ & $(0.195)$ \\
\hline \multirow[t]{2}{*}{ Treatment $\mathrm{B} \times$ Male } & 0.155 & 0.059 & -0.105 & $-0.409 * *$ & 0.0849 & -0.0121 \\
\hline & $(0.157)$ & $(0.182)$ & $(0.243)$ & $(0.194)$ & $(0.285)$ & $(0.190)$ \\
\hline Obs. & 1,138 & 1,091 & 1,137 & 1,085 & 987 & 1,088 \\
\hline $\mathrm{R} 2$ & 0.053 & 0.123 & 0.159 & 0.018 & 0.177 & 0.156 \\
\hline \multicolumn{7}{|c|}{ Panel B: Respondents with beyond primary education } \\
\hline \multirow[t]{2}{*}{ Treatment A } & 0.121 & 0.066 & $0.186^{* *}$ & $0.134 * *$ & $0.237 * *$ & 0.110 \\
\hline & $(0.095)$ & $(0.082)$ & $(0.077)$ & $(0.065)$ & $(0.100)$ & $(0.082)$ \\
\hline \multirow[t]{2}{*}{ Treatment B } & 0.149 & 0.044 & 0.064 & -0.044 & 0.128 & 0.104 \\
\hline & $(0.091)$ & $(0.081)$ & $(0.069)$ & $(0.100)$ & $(0.112)$ & $(0.106)$ \\
\hline \multirow[t]{2}{*}{ Educated } & 0.165 & $0.303 * * *$ & $0.335 * * *$ & $0.184^{*}$ & 0.055 & $0.228 * *$ \\
\hline & $(0.105)$ & $(0.106)$ & $(0.098)$ & $(0.108)$ & $(0.113)$ & $(0.100)$ \\
\hline \multirow[t]{2}{*}{ Treatment $\mathrm{A} \times$ Educated } & 0.126 & -0.053 & -0.032 & -0.102 & 0.229 & 0.032 \\
\hline & $(0.147)$ & $(0.147)$ & $(0.164)$ & $(0.139)$ & $(0.215)$ & $(0.168)$ \\
\hline \multirow[t]{2}{*}{ Treatment $\mathrm{B} \times$ Educated } & -0.256 & -0.107 & -0.174 & 0.037 & 0.169 & 0.199 \\
\hline & $(0.164)$ & $(0.174)$ & $(0.156)$ & $(0.187)$ & $(0.267)$ & $(0.138)$ \\
\hline Obs. & 1,162 & 1,114 & 1,161 & 1,108 & 1,007 & 1,111 \\
\hline \multirow{2}{*}{\multicolumn{7}{|c|}{ anel C: Respondent }} \\
\hline & & & & & & \\
\hline \multirow[t]{2}{*}{ Treatment A } & 0.099 & -0.140 & $0.265 * *$ & $0.162 *$ & $0.198^{*}$ & 0.084 \\
\hline & $(0.105)$ & $(0.0942)$ & $(0.105)$ & $(0.087)$ & $(0.110)$ & $(0.118)$ \\
\hline \multirow[t]{2}{*}{ Treatment B } & 0.092 & -0.121 & 0.161 & -0.068 & 0.071 & 0.100 \\
\hline & $(0.099)$ & $(0.104)$ & $(0.108)$ & $(0.099)$ & $(0.109)$ & $(0.137)$ \\
\hline \multirow[t]{2}{*}{ Fin. literate } & 0.090 & -0.122 & $0.261 * *$ & 0.046 & 0.055 & 0.118 \\
\hline & $(0.132)$ & $(0.079)$ & $(0.111)$ & $(0.095)$ & $(0.091)$ & $(0.093)$ \\
\hline \multirow{2}{*}{ Treatment $\mathrm{A} \times$ Fin. literate } & 0.079 & $0.336 * *$ & -0.199 & -0.106 & 0.145 & 0.036 \\
\hline & $(0.143)$ & $(0.132)$ & $(0.143)$ & $(0.131)$ & $(0.143)$ & $(0.136)$ \\
\hline \multirow[t]{2}{*}{ Treatment $\mathrm{B} \times$ Fin. literate } & -0.019 & $0.250 *$ & $-0.283^{* *}$ & 0.060 & 0.188 & 0.102 \\
\hline & $(0.154)$ & $(0.146)$ & $(0.142)$ & $(0.124)$ & $(0.166)$ & $(0.160)$ \\
\hline Obs. & 1,162 & 1,114 & 1,161 & 1,108 & 1,007 & 1,111 \\
\hline $\mathrm{R}^{2}$ & 0.052 & 0.115 & 0.158 & 0.010 & 0.150 & 0.136 \\
\hline Clusters & 83 & 83 & 83 & 83 & 83 & 83 \\
\hline District Fes & yes & yes & yes & yes & yes & yes \\
\hline$y_{(t-1)}$ controls & yes & yes & yes & yes & yes & yes \\
\hline \multicolumn{7}{|c|}{$\begin{array}{l}\text { Notes: Panel A shows results by gender, with "male" being an indicator variable for male respondents. Panel B shows } \\
\text { interactions between treatments and education with "Educated" being an indicator identifying respondents with above } \\
\text { primary education at baseline. Panel C reports interactions between the treatments and baseline financial literacy with "Fin } \\
\text { literate" being an indicator for a respondent scoring higher on the baseline financial literacy assessment than the average } \\
\text { respondent in the full baseline sample. Standard errors, clustered at the market-level, in parentheses. }{ }^{*} p<0.1,{ }^{* *} p<0.05 \text {, } \\
p<0.01 \text {. }\end{array}$} \\
\hline
\end{tabular}




\section{Appendix \\ (online appendix not intended for print publication) \\ to accompany \\ "Active learning fosters financial behavior: \\ Experimental evidence"}

Appendix A: Supplementary tables and figures

Appendix B: Robustness checks

Appendix C: Measuring financial literacy 


\section{Appendix A: Supplementary tables and figures}

\section{Figure A1: Timeline}

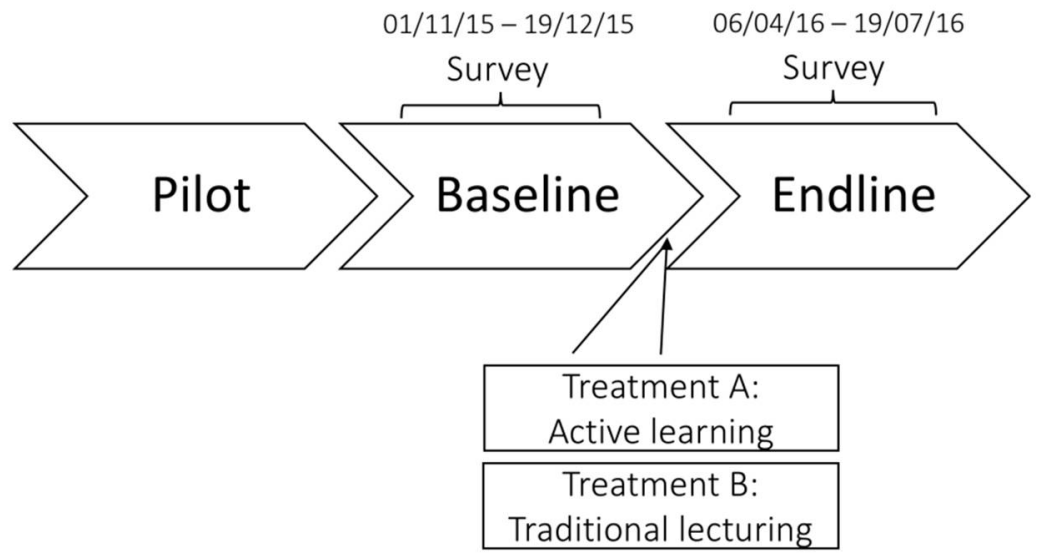


Table A1: Overview of financial education treatments

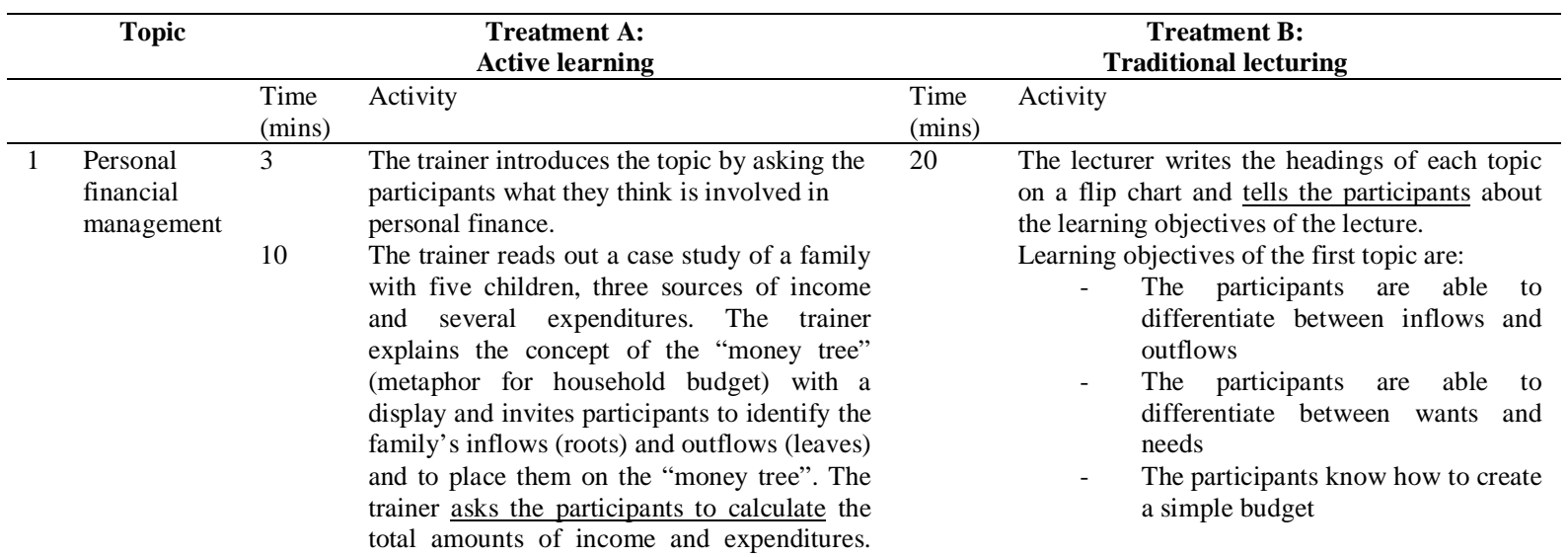

The lecturer starts with the topic of "personal financial management" and discusses the following keywords:

$\begin{array}{ll}\text { - } & \text { Financial priorities (separating } \\ \text { needs from wants) } & \text { What to use money for: spend, save, } \\ & \text { invest } \\ \text { - } & \text { Inflows/outflows } \\ \text { - } \quad \text { Budget } \\ \text { - } \quad \text { Setting goals and targets } \\ \text { - } \quad \text { Keeping track of spending } \\ \text { lecturer asks the participants whether they }\end{array}$

4 The trainer introduces the new family budget (after removing the "wants") and links it to the money tree. A picture of a written household budget is shown to the participants and the trainer asks the participants to give their views on how the family could spend the resulting surplus.

3 The session is being wrapped up by asking the participants how they would rate the importance of financial management and whether the introduced concepts are relevant for their own lives.

2 Savings 3 The trainer, again, refers to the case of the hypothetical family and pins up a definition of "saving" followed by personal questions to the participants: Who is saving? What are you saving for? How often are you saving? Why are you saving?

Trainer pins mentioned reasons on a poster and adds those mentioned and notion model cards.

8 The trainer introduces different ways to save (account, cash, durables,...) and explains that each way of saving comes with a specific "ease of access and return" profile and that these generally resemble conflicting goals. The trainer now asks the participants to indicate their preferences with regard to this trade-off by means of placing themselves on a line on the floor where the far left of the continuum indicates "easy to access" and the far right indicates "high return". Trainer asks the participants to share the rationale behind their decisions.

The trainer now chooses one example of saving forms at a time and asks participants where they would place the different examples of ways of saving. The trainer encourages discussion about these decisions.

The lecturer asks the participants whether they have questions or comments.
The lecturer writes the topic of this section on a flip chart and defines the learning objectives:

- $\quad$ The participants know the meaning of savings

- $\quad$ The participants know at least 3 ways to save

- The participants know at least 2 benefits of savings

- The participants know the trade-off between ease of access (liquidity) and return

The lecturer writes the following keywords on a flipchart and discusses the topics with the participants.

$$
\begin{aligned}
& \text { Saving in kind vs. in cash } \\
& \text { Conflicting savings-goals: } \\
& \text { safety } \\
& \text { return } \\
& \text { ease of access }
\end{aligned}
$$

The lecturer draws a line on the flipchart, illustrating the ease of access and return tradeoff. The lecturer illustrates this using the examples of 'money under the mattress' and 'money in a fixed deposit account' on the line. 
asks the participant to cross out wrong statements. This results in a collection of ten statements on the benefits of savings which are subsequently repeated.

The trainer asks the participants to share their experiences with loans and subsequently displays a card with a formal definition of a loan.

The trainer refers to the hypothetical family and adds more detail to their financial situation. The participants are asked to identify three things that the hypothetical family plans to borrow money for (consumption vs. productive investments).

The trainer asks the participant what they consider sensible and non-sensible reasons to take up a loan. The participants use cards with example pictures and cluster these on a poster into the two categories. Loans are evaluated on the basis on whether they may put to productive use. Participants agree on the advice they would give this family on which loan to take and which loan not to take.

The trainer informs the group that a loan comes with (direct and indirect) costs and is usually tied to specific conditions. The participants are asked to place cards with the various costs of borrowing on the poster.

The trainer concludes with the station and asks whether the participants have any further questions regarding borrowing. The trainer cautions the participants against the use of expensive credit to finance consumption expenditures.

The trainer pins up a card with the word "investment" and asks the participants for a definition. The trainer complements this discussion with a formal definition.

The trainer requests the participants to reflect on the discussion they have just had about and asks the participants to share their experiences with regard to investments they have made themselves. The trainer then introduces illustrative cards that display either consumption or investment activates and asks participant to assess whether the cards indicate productive investments.

The trainer informs participants that each form of investment comes with a unique "safety-return" profile. "Safety" and "return" represent conflicting goals and that an investment always comes with certain risks. The trainer now asks the participants to indicate their preferences with regard to this trade-off by means of placing themselves on a line where the far left of the continuum indicates "safety" and the far right indicates "high return". Trainer asks the participants to share the rationale behind their decisions.

The trainer now chooses one example of investment forms at a time and asks participants where they would place the different examples of ways of investing. The trainer encourages discussion about these decisions. have questions or comments.

The lecturer writes the topic of this section on a flip chart and defines the learning objectives:

- The participants are able to differentiate between a sensible and non-sensible reasons to take up a loan

- $\quad$ The participants know typical direct and indirect costs of borrowing

The lecturer writes the following keywords on a flipchart and discusses the topics with the participants:

\section{$\underline{\text { Reasons for borrowing: }}$}

to finance productive investments

to finance consumption goods

to cater for emergencies

\section{The cost of borrowing}

Direct costs vs. indirect costs of borrowing

Questions to ask a lender before taking up a loan:

\section{Interest rate}

Collateral

Installments (how much, how often)

Penalties for delinquency

The lecturer asks the participants whether they have questions or comments.

The lecturer writes the topic of this section on a flip chart and defines the learning objectives:

- $\quad$ The participants know what an investment is

- The participants know different forms of investment

- The participants know the trade-off between safety (minimal risk) and return

The lecturer writes the following keywords on a flipchart and discusses the topics with the participants:

Forms of investments:

$$
\begin{aligned}
& \text { Animals } \\
& \text { Land } \\
& \text { Business (own and other's) } \\
& \text { Buildings }
\end{aligned}
$$

Why invest?

Create wealth and security Increase the ability to earn more income

Planning for old age

- Create employment opportunities for oneself and others 
The trainer refers to the case of the hypothetical family and asks the participants to summarize the investment decisions the family has taken. The trainer asks the participants to summarize the associated risks and benefits of these investment decisions. The trainer asks the participants whether they are aware of strategies to manage these risks. Afterwards he introduces the notion of formal and informal insurance, as well as insurance through diversification.

Financial service providers -continued-
The trainer refers to the hypothetical case of the family and asks the participants to name institutions where the family could save money at. The trainer classifies these answers into regulated and non-regulated institutions (by the central bank).
The trainer discusses advantages and disadvantages of financial institutions regulated or not-regulated by the central bank and asks the participants to give the hypothetical family advice on where to save the money.

Trainer introduces the aspect of rights and responsibilities of consumers of financial services. The trainer informs participants that they have rights and responsibilities as Financial service consumers/users. The trainer asks the participants to complete a true/false exercise on statements related to consumer protection rights.

The trainer moves to a discussion of payment services and asks the participants to name different ways of transferring money (i.e. for remittances) and asks the participants to discuss the costs attached to these services. The trainer closes the station by encouraging the participants to compare prices and to analyze all options available to them to make The lecturer writes the topic of this section on
flip chart and defines the learning objectives:

- The participants know the difference between regulated and unregulated financial service providers

- The participants know rights and responsibilities of financial service users

- $\quad$ The participants know different options to make money-transfers and payments

The lecturer writes the following keywords on a flipchart and discusses the topics with the participants:

Classification of financial services sector in Uganda:

- Tier i - Commercial Banks

Tier ii - Credit Institutions

Tier iii - Micro Deposit Taking

Institutions

- Tier iv - Other Financial Institutions (e.g. VSLAs, ROSCA Unregulated vs. regultated by the Bank of Uganda (Tier i to iii)

- $\quad$ Rights and responsibilities of consumers

\section{- $\quad$ Payments:}

- Understanding the costs involved - Keeping ones personal information secure

- $\quad$ Make safer payments (track who got it) Mobile money \& transaction costs Automated Teller Machines (ATMs)

The lecturer asks the participants whether they have questions or comments. 


\section{Further checks of randomization balance.}

Table A2 reports additional summary statistics for a rich set of covariates in the full sample and each experimental condition at baseline.

\section{< Table A2 about here>}

Panel $A$ shows variables that measure characteristics at the household level. The average household size is 6.83 people, with an average of 2.17 adults contributing to the household's income, a mean of 4.17 children being supported and a mean of 0.36 adults who do not generate external income, such as elderly (plus 0.13 for missing values). The mean (winsorized) monthly household consumption value is about 593,000 UGX.

Panel $B$ reports variables at the respondent-level. The mean (winsorized) monthly individual income is around 220,000 UGX (about 60 USD). Household consumption is higher than hypothetical added individual incomes because of subsistence farming, being reported by 83 percent of the sample. Our sample is predominantly comprised of women $(80 \%)$ and the average age is 36.2 years. On average, participants have been vending goods on markets for 7.4 years. Only 14 percent report to be selling non-food items (mainly second-hand clothing). The other 86 percent of the sample sell either fresh agricultural products or prepared food. Over two thirds (68 percent) are able to read and write in at least one language and about 25 percent participated in education beyond primary school. About two thirds of the sample report to be married. 70 percent of the respondents state that they are the main contributors of income to the household, while 55 percent report to be the "head of the household". Only 16 percent report to be economically dependent on others. Responding to another survey question, 22 percent of the sample receive aid or assistance from either NGOs or government programs.

We elicit general and domain-specific risk attitudes using common non-incentivized survey items popularized by Dohmen et al. (2011). These survey-items ask for willingness to 
take risk on a 0 to 10 scale with highest risk tolerance at 10 . On average, respondents are relatively risk-averse. This applies both to the general risk attitudes (mean of 3.61) and to risk attitudes regarding the financial domain (mean of 3.78). The mode and median are at 3 for both the general and the domain-specific case, and thus lower than for a representative sample of the German population with a modal response of 5 (Dohmen et al., 2011). Our survey also includes a measure of numeracy and several psychological variables which are standardized into z-scores to have a mean of zero and a standard-deviation equal to one in the pooled sample. These are mainly used as controls, for the purpose of probing randomization balance in multiple dimensions, and for the investigation of possible causal mechanisms (see Section $5)$.

Panel $C$ shows descriptive statistics for outcome measures of financial literacy and financial behavior indices (standardized to have a mean of zero and a standard deviation equal to one) at baseline. Again, the outcomes are clearly balanced as no statistically significant differences exist. This also extends to an analysis of the descriptive statistics for individual index components in Table A3.

\section{< Table A3 about here>}

Apart from one outcome within the borrowing-index, all components are fully balanced at baseline and a joint test of orthogonality, again, confirms that the three groups are balanced with respect to their levels of the main outcome variables at baseline $(p=0.687)$. 
Table A2: Additional descriptive statistics and randomization balance for a rich set of baseline covariates

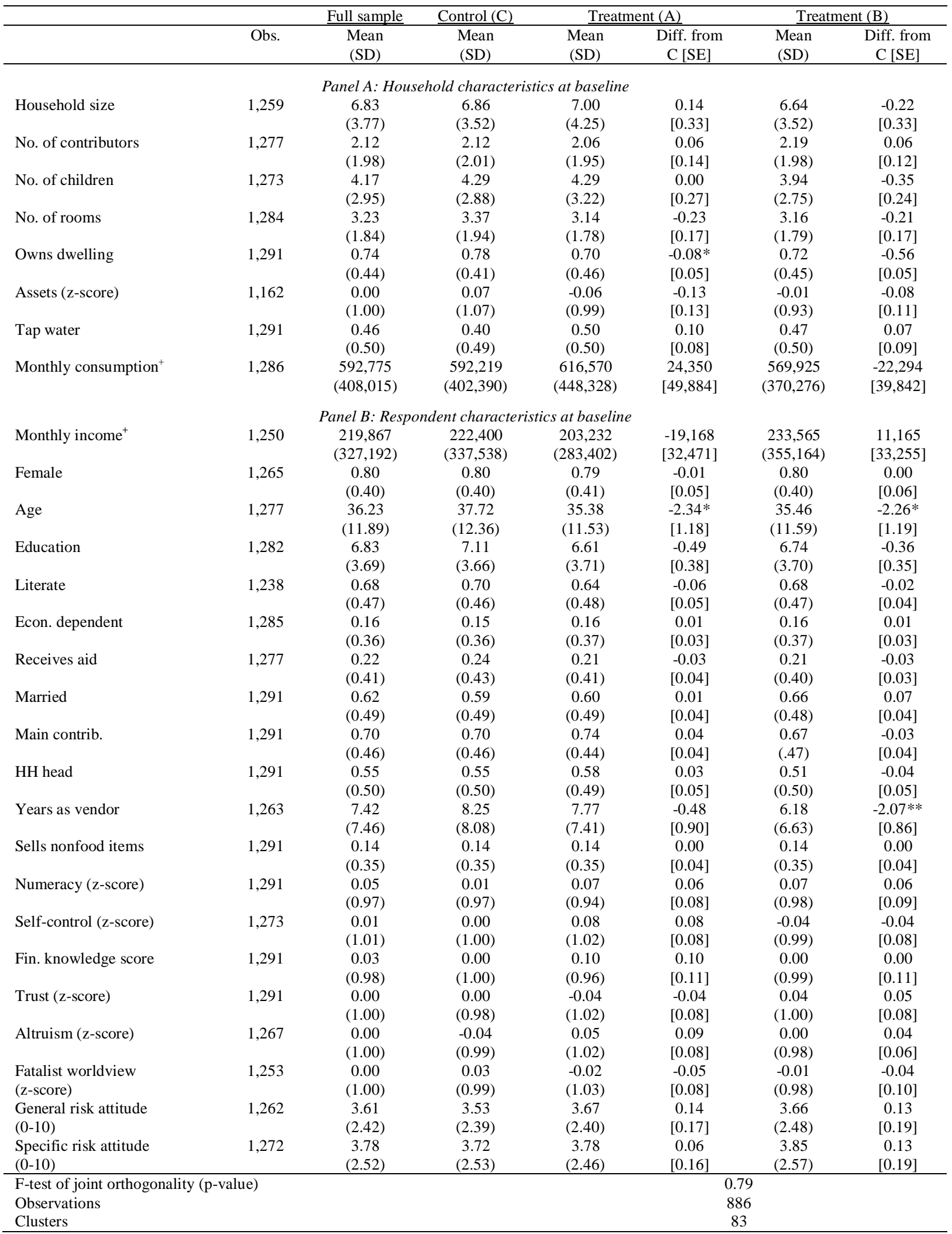


Table A3: Descriptive statistics and randomization-balance for components of outcome indices at baseline

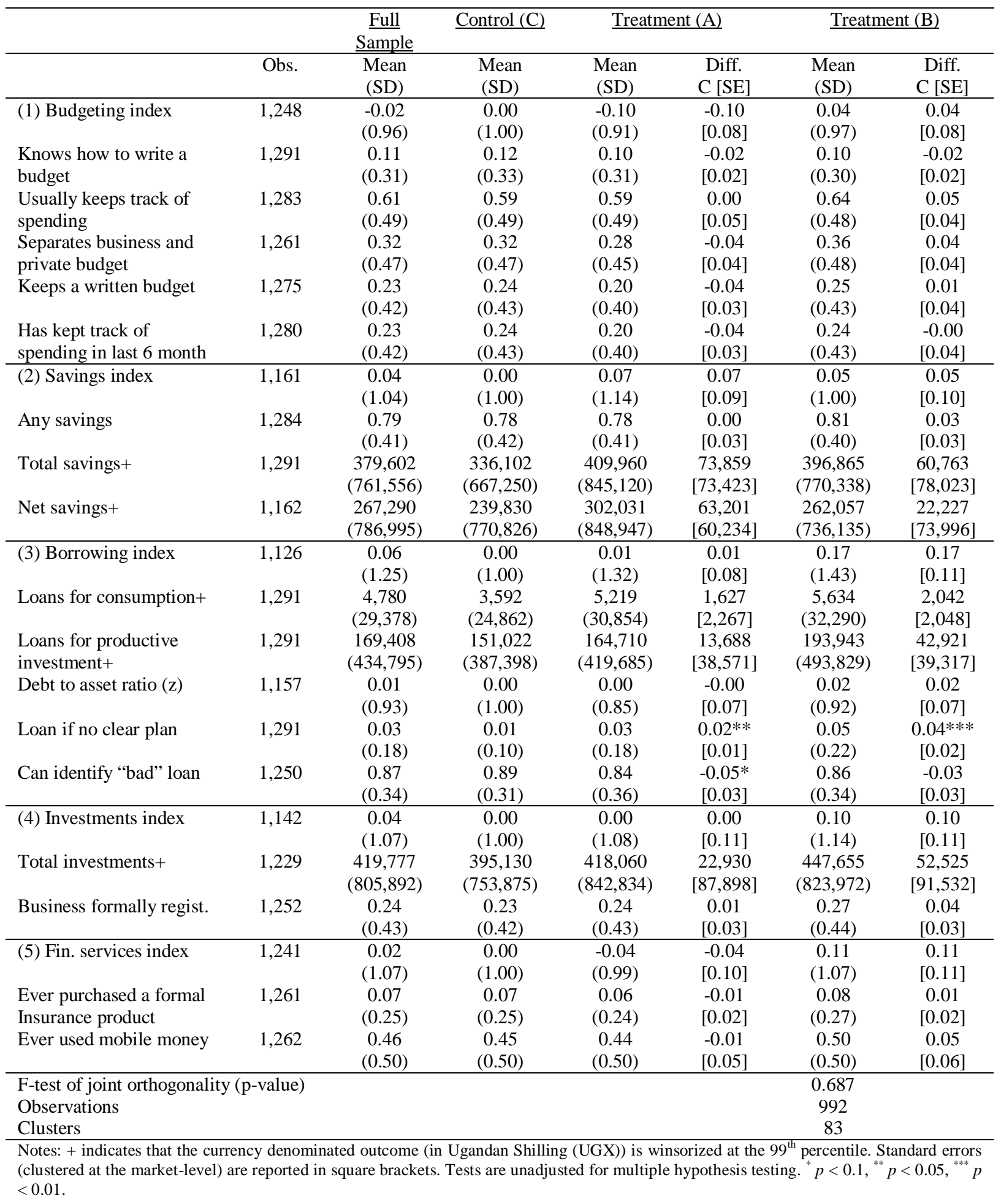




\section{Treatment effects on further components within indices.}

The budgeting index consists of five binary items capturing changes in budgeting and record keeping behavior (see Table A4). These binary items measure whether respondents know how to create a written budget and ask for budgeting behavior, i.e. separating personal and business records and regularly keeping track of expenditures. Of the ten reported marginal effects (considering the two financial education treatments), five have a size of about 0.04 to 0.05 percentage point improvement (on averages of 9 to 66 percent in the control group), out of which four have a positive sign; however, the single negatively signed coefficient is the only significant coefficient, indicating adverse effects of treatment B on the ability to correctly draft a budget. Thus, overall average effects in this domain are insignificant from zero.

\section{< Table A4 about here>}

The borrowing index consists of six items (see Table A5). Items aggregated into this index capture the structure and volume of debt along with a proxy for debt-bearing capacity and binary items indicating whether respondents would take up loans without a plan or are able to distinguish between sensible and non-sensible reasons to take up a loan with interest. As predicted by the existing literature, treatment effects in this domain are very modest, especially with regard to financial outcomes (cf. Miller et al., 2015; Kaiser and Menkhoff, 2017). The coefficients on the volume of loans intended for consumption purposes and productive investments are extremely small and, thus, insignificant from zero. The same is true for the effect on the asset to debt ratio proxying the debt-bearing capacity and the ability of respondents to distinguish between sensible and non-sensible reasons to take up a loan with interest in hypothetical settings. There is a significant effect for the active learning treatment, however, on the self-report of respondents to take-up a loan (if offered) when they had no clear plan of how to use the money: approximately 14 percent of the control group report to 
be willing to take up a loan, even if they had no clear plan on how to use the borrowed amount. The marginal effect of the active learning treatment results in a 5.5 percentage point decrease in the willingness to take up a loan without a clear plan of its utilization. Thus, this particular effect is relatively large (39.2 percent relative to the control group) resulting in the reported overall small and marginally-significant positive impact on the aggregated index discussed above. Treatment B, on the other hand, has a much smaller effect (reduction of 3.8 percentage points or 27 percent) and is statistically insignificant from zero.

< Table A5 about here>

Finally, the financial service index (see Table A6) includes two binary items indicating whether respondents were ever covered by a formal insurance product or if they have ever used mobile money (payment) services. Both treatments seem to have the expected positive sign, and the coefficient of treatment A on mobile money use is marginally significant. 44 percent of the control group report to have ever used mobile money services and active learning has a marginal effect of 6.3 percentage points on mobile money use. Lecturing, however, has a much smaller effect size (3.5 percentage points) and is statistically insignificant from zero. Both treatments have zero-effects on formal insurance use (an increase of 0.6 and 5 percentage points) relative to a control-group mean of 9.9 percent).

\section{< Table A6 about here>}

Overall, even if the three aggregated indices on budgeting, and financial services do not show the desired significant coefficients (see Table 3), a closer look at the disaggregated items suggests that there are selected subdomains where treatments which were more focused or more intensive may be able to impact financial behavior.

\section{Reference in Appendix A}

Dohmen, T., Falk, A., Huffman, D., Sunde, U., Schupp, J., and Wagner, G. G. (2011). Individual risk attitudes: Measurement, determinants, and behavioral consequences. Journal of the European Economic Association, 9(3): 522-550. 
Table A4: Budgeting index - individual components

\begin{tabular}{lccccc}
\hline & $\begin{array}{c}(1) \\
\text { Knows how to Usually keeps } \\
\text { write a budget } \\
\text { track of } \\
\text { spending }\end{array}$ & $\begin{array}{c}(3) \\
\text { Separates } \\
\text { business and } \\
\text { private budget }\end{array}$ & $\begin{array}{c}(4) \\
\text { Keeps a } \\
\text { written budget }\end{array}$ & $\begin{array}{c}\text { Has kept track of } \\
\text { spending in last 6 } \\
\text { month }\end{array}$ \\
\hline Treatment A & 0.004 & 0.046 & 0.046 & -0.008 & -0.007 \\
Treatment B & $(0.025)$ & $(0.041)$ & $(0.038)$ & $(0.037)$ & $(0.035)$ \\
& $-0.047^{* *}$ & 0.039 & 0.064 & 0.003 & 0.007 \\
\hline$A-B=0$ (p-value) & $(0.021)$ & $(0.039)$ & $(0.043)$ & $(0.034)$ & $(0.033)$ \\
$\mathrm{R}^{2}$ & $0.015^{* *}$ & 0.842 & 0.661 & 0.751 & 0.681 \\
Mean of $y_{t}$ in C & 0.011 & 0.046 & 0.032 & 0.149 & 0.149 \\
Observations & 0.098 & 0.665 & 0.450 & 0.284 & 0.274 \\
Clusters & 1,162 & 1,160 & 1,131 & 1,150 & 1,153 \\
District FEs & 83 & 83 & 83 & 83 & 83 \\
$y_{(t-1)}$ covariate & yes & yes & yes & yes & yes \\
\hline
\end{tabular}

Notes: Coefficients show results from linear probability models. All models include the lagged outcome at baseline and district-level fixed effects. Standard errors (clustered at the market-level) are reported in parentheses. ${ }^{*} p<0.1,{ }^{* * *} p<0.05$, $p<0.01$

Table A5: Borrowing index - individual components

\begin{tabular}{lccccc}
\hline & $\begin{array}{c}(1) \\
\text { Loans for } \\
\text { consumption* }\end{array}$ & $\begin{array}{c}(2) \\
\text { Loans for } \\
\text { productive } \\
\text { investment }\end{array}$ & $\begin{array}{c}(3) \\
\text { Debt to asset ratio } \\
\text { (z-score)* }\end{array}$ & $\begin{array}{c}(4) \\
\text { Would take loan Can correctly } \\
\text { if no clear plan* } \\
\text { identify a } \\
\text { "bad" loan }\end{array}$ \\
\hline Treatment A & 2,142 & $-15,615$ & -0.089 & $-0.055^{* *}$ & -0.001 \\
Treatment B & $(5,840)$ & $(37,458)$ & $(0.074)$ & $(0.023)$ & $(0.010)$ \\
& 12,855 & $-43,846$ & 0.006 & -0.038 & 0.004 \\
\hline$A-B=0$ (p-value) & $(9,345)$ & $(36,785)$ & $(0.090)$ & $(0.023)$ & $(0.010)$ \\
$\mathrm{R}^{2}$ & 0.231 & 0.4043 & 0.268 & 0.495 & 0.900 \\
Mean (SD) of $y_{t}$ in control & 0.010 & 0.108 & 0.119 & 0.014 & 0.006 \\
group & 20,763 & 151,021 & 0.000 & 0.139 & 0.029 \\
Observations & $(98,688)$ & $(387,398)$ & $(1.000)$ & $(0.346)$ & $(0.167)$ \\
Clusters & 1,158 & 1,158 & 1,153 & 1,116 & 1,162 \\
District FEs & 83 & 83 & 83 & 83 & 83 \\
$y_{(t-1)}$ covariate & yes & yes & yes & yes & yes \\
\hline
\end{tabular}

Notes: Columns (1) to (3) show OLS-regressions. Columns (4) and (5) are linear probability models. Dependent variable in Column (1) is the amount of credit intended for consumption purposes. Dependent variable I Column (2) is the amount of debt intended for productive investments. Dependent variable in Column (3) reports the ratio between debt and household assets and is transformed to a z-score. Dependent variables in Columns (4) and (5) are binary items reporting whether a respondent would be willing to take up a loan if he or she had no plans on how to use the money or whether a respondent can separate between good and bad reasons to take up a loan as stated in a hypothetical example. Items marked with an asterisk $(*)$ are later rescaled for the composition of the index such that positive values indicate better outcomes. All models include the lagged outcome at baseline and district-level fixed effects. + indicates that the currency denominated outcome (in Ugandan Shilling (UGX)) is winsorized at the $99^{\text {th }}$ percentile. Standard errors (clustered at the market-level) are reported in parentheses. ${ }^{*} p<0.1,{ }^{* *} p<0.05,{ }^{* * *} p<0.01$. 
Table A6: Financial services index - individual components

\begin{tabular}{|c|c|c|}
\hline & $\begin{array}{c}\text { (1) } \\
\text { Ever purchased a formal } \\
\text { insurance product }\end{array}$ & $\begin{array}{l}\text { (2) } \\
\text { Has ever used mobile } \\
\text { money }\end{array}$ \\
\hline \multirow[t]{2}{*}{ Treatment A } & 0.006 & $0.063 *$ \\
\hline & $(0.027)$ & $(0.037)$ \\
\hline \multirow[t]{2}{*}{ Treatment B } & 0.050 & 0.035 \\
\hline & $(0.035)$ & $(0.045)$ \\
\hline$A-B=0$ (p-value $)$ & 0.159 & 0.514 \\
\hline $\mathrm{R}^{2}$ & 0.036 & 0.194 \\
\hline Mean (SD) of $y_{t}$ & 0.099 & 0.442 \\
\hline in control group & $(0.299)$ & $(0.497)$ \\
\hline Observations & 1,133 & 1,136 \\
\hline Clusters & 83 & 83 \\
\hline District FEs & yes & yes \\
\hline$y_{(t-1)}$ covariate & yes & yes \\
\hline
\end{tabular}

Notes: Coefficients show results from linear probability models. All models include the lagged outcome at baseline and district-level fixed effects. Standard errors (clustered at the market-level) are reported in parentheses. ${ }^{*} p<0.1,{ }^{* *} p<0.05$, $p<0.01$

Table A7: Descriptive statistics for intermediating index variables at baseline

\begin{tabular}{|c|c|c|c|c|c|c|c|}
\hline & & $\underline{\text { Full }}$ Sample & Control (C) & Treat & $(\mathrm{A})$ & $\underline{\text { Treat }}$ & (B) \\
\hline & Obs. & $\begin{array}{c}\text { Mean } \\
(\mathrm{SD})\end{array}$ & $\begin{array}{c}\text { Mean } \\
\text { (SD) }\end{array}$ & $\begin{array}{c}\text { Mean } \\
\text { (SD) }\end{array}$ & $\begin{array}{c}\text { Diff. } \\
\text { C [SE] }\end{array}$ & $\begin{array}{c}\text { Mean } \\
(\mathrm{SD})\end{array}$ & $\begin{array}{c}\text { Diff. } \\
\mathrm{C}[\mathrm{SE}]\end{array}$ \\
\hline (1) Fin. literacy score & 1,291 & 0.03 & 0.00 & 0.10 & 0.10 & 0.00 & 0.00 \\
\hline & & $(0.98)$ & $(1.00)$ & $(0.96)$ & {$[0.11]$} & $(0.99)$ & {$[0.11]$} \\
\hline FL Item 1 & 1,291 & 0.62 & 0.63 & 0.61 & -0.02 & 0.62 & -0.01 \\
\hline & & $(0.48)$ & $(0.48)$ & $(0.49)$ & {$[0.48]$} & $(0.49)$ & {$[0.05]$} \\
\hline FL Item 2 & 1,291 & 0.60 & 0.59 & 0.60 & 0.01 & 0.62 & 0.03 \\
\hline & & $(0.49)$ & $(0.49)$ & $(0.49)$ & {$[0.05]$} & $(0.49)$ & {$[0.05]$} \\
\hline FL Item 3 & 1,291 & 0.47 & 0.43 & 0.51 & 0.08 & 0.47 & 0.04 \\
\hline & & $(0.50)$ & $(0.50)$ & $(0.50)$ & {$[0.03]$} & $(0.50)$ & {$[0.04]$} \\
\hline FL Item 4 & 1,291 & 0.44 & 0.45 & 0.50 & 0.05 & 0.39 & -0.06 \\
\hline & & $(0.50)$ & $(0.50)$ & $(0.50)$ & {$[0.05]$} & $(0.49)$ & {$[0.05]$} \\
\hline FL Item 5 & 1,291 & 0.39 & 0.38 & 0.43 & 0.04 & 0.37 & -0.01 \\
\hline & & $(0.49)$ & $(0.49)$ & $(0.50)$ & {$[0.04]$} & $(0.48)$ & {$[0.05]$} \\
\hline (2) Fin. confidence & 1,259 & -0.05 & 0.00 & -0.04 & -0.04 & -0.11 & -0.11 \\
\hline (z-score) & & $(0.99)$ & $(1.00)$ & $(0.98)$ & {$[0.11]$} & $(1.01)$ & {$[0.10]$} \\
\hline (3) Self-control & 1,273 & 0.01 & 0.00 & 0.08 & 0.08 & -0.04 & -0.04 \\
\hline (z-score) & & $(1.01)$ & $(1.00)$ & $(1.02)$ & {$[0.08]$} & $(0.99)$ & {$[0.08]$} \\
\hline F-test of joint orthogona & -value) & & & & & 0.32 & \\
\hline Observations & & & & & & 1,248 & \\
\hline Clusters & & & & & & 83 & \\
\hline $\begin{array}{l}\text { Notes: For further inforn } \\
\text { aggregate measure (equa } \\
\text { for the control group) of } \\
\text { complain, do you think } \\
\text { not lead to anything?" } \\
\text { products." (disagree stro } \\
\text { can choose the loan tha } \\
\text { statements best describe } \\
\text { before making my decisi } \\
\text { at all (d) I looked around } \\
\text { question: "If you get mol } \\
\text { (clustered at the market- } \\
{ }_{* * *} p<0.05,{ }^{* * *} p<0.01 .\end{array}$ & $\begin{array}{l}\text { ollowing } \\
\text { he finan } \\
\text { (ii) "I a } \\
\text { - agree } \\
\text { t suits } n \\
\text { you las } \\
\text { ) I cons } \\
\text { there we } \\
\text { lo you te }\end{array}$ & $\begin{array}{l}\text { idual com } \\
\text { re index } \\
r \text { items: ( } \\
\text { service pr } \\
\text { nfident e } \\
\text { gly). (iii) } \\
\text { ecific ne } \\
\text { se a finan } \\
\text { d the vari } \\
\text { other pr } \\
\text { spend it }\end{array}$ & $\begin{array}{l}\text { ents of finan } \\
\text { s component } \\
\text { In case you at } \\
\text { der is more p } \\
\text { gh to approa } \\
\text { m confident t } \\
\text { (disagree st } \\
\text { product? (a) } \\
\text { products fror } \\
\text { cts to conside } \\
\text { quickly? (a) }\end{array}$ & $\begin{array}{l}\text { iteracy s } \\
\text { l standar } \\
\text { ssatisfiec } \\
\text { ful than } \\
\text { bank an } \\
\text { Imong a } \\
\text { ly - agr } \\
\text { nsidered } \\
\text { e compa } \\
\text { elf-contr } \\
\text { (b) som }\end{array}$ & $\begin{array}{l}\text { ee Appe } \\
\text { to have } \\
\text { a financ } \\
\text { and that } \\
\text { questio } \\
\text { of loans } \\
\text { ongly). } \\
\text { al produ } \\
\text { I didn' } \\
\text { ssessed } \\
\text { s (c) rare }\end{array}$ & $\begin{array}{l}\text { C. Fin. c } \\
\text { o mean at } \\
\text { ervice pr } \\
\text { complaint } \\
\text { learn m } \\
\text { red by dif } \\
\text { Which of } \\
\text { om differ } \\
\text { sider any } \\
\text { gh the fo } \\
\text { l) never. }\end{array}$ & $\begin{array}{l}\text { ence is an } \\
\text { SD of one } \\
r \text { and you } \\
\text { therefore } \\
\text { bout their } \\
\text { t banks, I } \\
\text { following } \\
\text { ompanies } \\
\text { products } \\
\text { ng survey } \\
\text { ard errors } \\
p<0.1 \text {, }\end{array}$ \\
\hline
\end{tabular}


Table A8: Analysis of effects on individual items in the FL-score (ANCOVA)

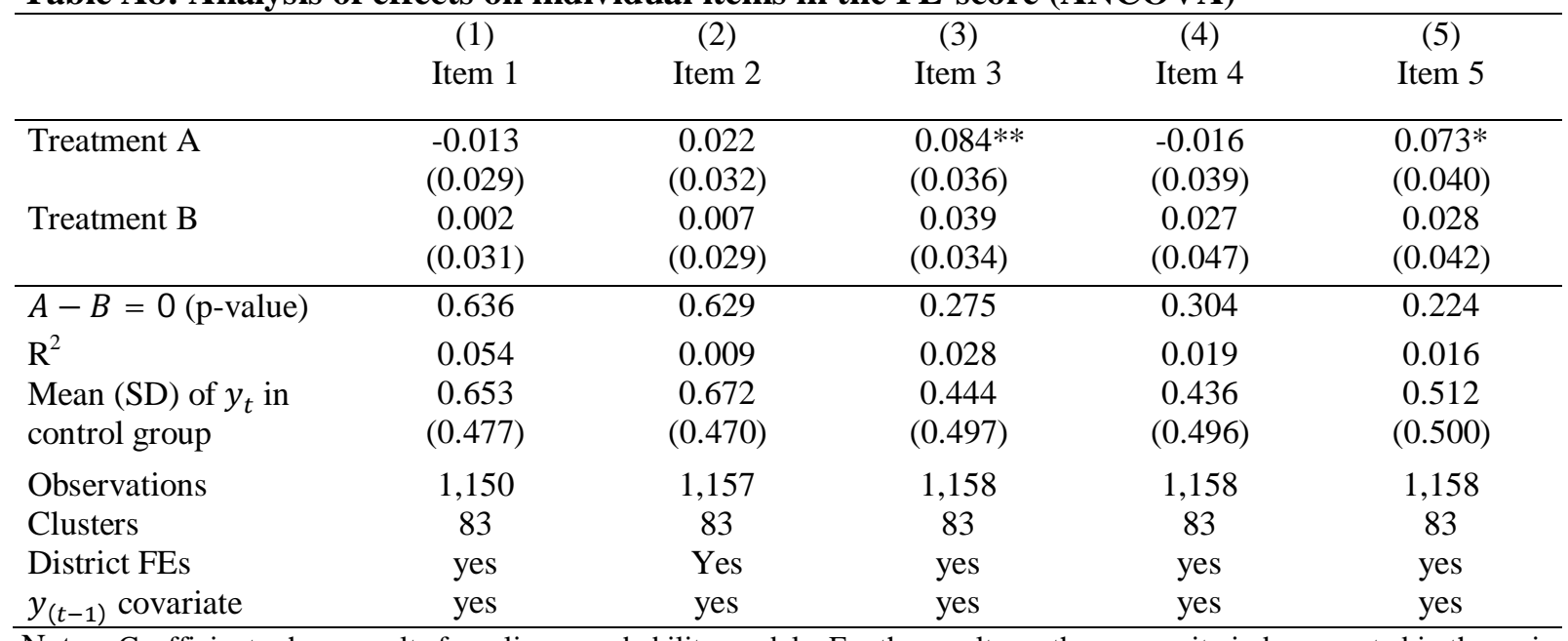

Notes: Coefficients show results from linear probability models. For the results on the composite index reported in the main text, predicted scores from the 2PLM-IRT-model are used (cf. Appendix C). All models include the lagged outcome at baseline and district-level fixed effects. Standard errors (clustered at the market-level) are reported in parentheses. ${ }^{*} p<0.1$, ${ }^{* * *} p<0.05,{ }^{* * * *} p<0.01$. 


\section{Appendix B: Robustness checks}

This appendix mainly deals with the issue of selective attrition and probes the sensitivity of our results to changes in the empirical strategy. In the following, we analyze determinants of attrition and examine the implications of attrition on the estimated treatment effects. Correcting for differential attrition according to treatment groups and districts through inverse-probability weighting of selection into endline yields similar results to an unweighted analysis that ignores attrition. More importantly, we estimate bounds for the treatment effects (A) and (B) under several plausible or extreme scenarios for outcomes of those who are not met at the follow-up survey. These analyses strongly support the findings of the analyses presented in the main text. Next, we show that simple OLS results using only the endline data are similar to the ANCOVA results. Finally, we show treatment effects on the measure of financial literacy using the more common raw sumscore rather than the predicted latent trait from the IRT model.

Selective attrition. As mentioned in Section 3.3, attrition varies between the treatment and control groups. At first glance, it appears that there is a significant effect of being assigned to treatment $\mathrm{B}$ on attrition. To investigate this issue, we first look at attrition per district: Just before our follow-up survey in April 2016, the districts of Bundibugyo and Kasese experienced violent outbreaks related to disputed local elections and tribal differences. These violent episodes lead to several deaths, military involvement and, according to local media, displacement of several thousand individuals from the district of Bundibugyo. 22 out of 83 markets are located in this district (and another 12 markets in the district of Kasese). These clusters make up roughly 39\% of individuals in our entire sample at baseline. Because randomization at the cluster-level was not stratified by district, the distribution of treatment groups along these clusters is heterogeneous: In the case of Bundibugyo, only $23 \%$ of clusters belong to the control group. Thus, $77 \%$ of clusters have been assigned to financial education 
treatment in the district. Out of these assigned to treatment, $52 \%$ have been assigned to treatment B which experiences the highest attrition. Thus, attrition appears may be driven by this exogenous shock.

To investigate determinants of attrition in a formal setting, we estimate a logit model of being absent at follow-up on the two treatment dummies and, alternatively include market or district fixed effects in this model.

$<$ Table B1 about here>

Column 1 of Table B1 shows marginal effects after logit without accounting for district-level effects. This indicated that those assigned to treatment are 5 percentage points (marginally significant) more likely drop out of the survey than the control group. Turning to Column 2 which included market dummies, however, shows that this result disappears when accounting for these market-level events. Similarly, the coefficient decreases in size when accounting for district fixed-effects: Column 3 shows results including district dummies with the abovementioned district of "Bundibugyo" being the omitted category. All of the other six districts are estimated to have lower attrition than Bundibugyo, further indicating that attrition is not endogenous but may be driven by this exogenous district and market-level shocks. To probe the sensitivity of our results to attrition, we next use the predicted probability to drop out from the study to adjust the regressions.

Inverse probability weighting. We weight all regressions with inverse probability of selection into endline tracking as estimated by a logit-model based in the specification in Column 3 of Table B1.

<Table B2 about here>

The results are near identical to the unweighted specification discussed in the main text.

Bounds estimates for the financial education treatments. To further address selective attrition, we estimate bounds for the worst-case scenarios for the treatment effects on the 
financial literacy and savings. Similar to Karlan and Valdivia (2011) and Drexler et al (2014), we follow Horrowitz and Manski (2000) and Lee (2002), and impute plausible values for missing observations to estimate bounds for the treatment effect. For the extreme lower bound, we impute the largest value of the $1^{\text {st }}$ percentile of each outcome variable in the observed distribution of $y^{*}$ to the attriters in the treatment groups, and the smallest value of $99^{\text {th }}$ percentile of the observed control-group distribution to the attriters in the control group. For the extreme upper bound, we impute the smallest value of the $99^{\text {th }}$ percentile of each outcome variable in the observed treatment distributions to the attriters in the treatment groups, and the largest value of the $1^{\text {st }}$ percentile of the observed control distribution to the attriters in the control group (cf. Karlan and Valdivia, 2011, p. 522). More plausible lower bounds are created by imputing missing values for the treatment groups $\mathrm{A}$ and $\mathrm{B}$ as their respective means for minus $0.1,0.25$, and 0.5 standard deviations of the observed distribution for the group. Missing values for the control group are imputed as the mean of the control group plus $0.1,0.25$, and 0.5 standard deviations, respectively. Plausible upper bounds for $0.1,0.25$, and 0.5 standard deviations are calculated analogously.

$<$ Table B3 about here>

Panel A of Table B3 shows the sensitivity of the unadjusted treatment effect to the uncertainty around attrition on the savings index. Encouragingly, the main result is unaffected by considering even extreme scenarios. Treatment $\mathrm{A}$ is always estimated to have larger (or less adverse in the extreme lower bound scenario) effects on savings. Additionally, differential treatment effects (test of equality of Treatment A and B) are rejected across the entire distribution of considered scenarios. Statistical and economic significance for treatment A is maintained up to a lower bound of -0.5 standard deviations. In contrast, treatment B never reaches statistical significance and the estimated scenario for the extreme upper bound 
results in a smaller coefficient than lower bound scenarios for treatment B up to -0.5 standard deviations.

Panel B of Table B3 shows results on the investment index. Again, treatment A is estimated to have larger coefficients than treatment B in several of the considered scenarios. The effect of treatment A remains to be relatively large and statistically significant up to a lower bound scenario of -0.4 standard deviations. Thus, the results presented here give strong support to conclude that the main results are not sensitive to selective attrition. With regard to the savings domain, differential treatment effects are significant regardless of even extreme assumptions about those who do not select into endline survey.

OLS using only endline data. Table B4 shows results using OLS and only the endline data. This approach yields less power and precision, and thus, is not preferred (McKenzie, 2012). Nevertheless, it may be reassuring that results are similar to the ANCOVA estimation. Treatment effects of treatment A and B are estimated to be even larger, however, with less precision.

\section{$<$ Table B4 about here >}

Standard FL-score. Table B5 shows regression-results using a standard sum score of correct answers as the measure of financial literacy. As the IRT-model clearly has better psychometric properties (cf. Appendix C), we do not prefer this procedure. However, it may be reassuring that effect sizes are similar and the difference in magnitude of the coefficients (unstandardized regression coefficient from OLS in Column1 and logged odds from orderedlogit and ordered-probit models) is similar to the result presented in the text, albeit with larger standard errors due to the relative imprecise measure of financial literacy.

< Table B5 about here >

\section{References in Appendix B}

Drexler, A., Fischer, G., and Schoar, A. (2014). Keeping it simple: Financial literacy and rules of thumb. American Economic Journal: Applied Economics, 6(2): 1-31. 
Horowitz, J. L. and Manski, C. F. (2000). Nonparametric analysis of randomized experiments with missing covariate and outcome data. Journal of the American Statistical Association, 95(449): 77-84.

Karlan, D. and Valdivia, M. (2011). Teaching entrepreneurship: Impact of business training on microfinance clients and institutions. Review of Economics and Statistics, 93(2): 510-527.

Lee, D.S. (2002). Trimming for bounds on treatment effects with missing outcomes. NBER Technical Working Paper 277.

McKenzie, D. (2012). Beyond baseline and follow-up: The case for more $\mathrm{T}$ in experiments. Journal of Development Economics, 99(2): 210-221. 
Table B1: Determinants of attrition

\begin{tabular}{lccc}
\hline & \multicolumn{3}{c}{ Binary for attrition } \\
\cline { 2 - 4 } & $(1)$ & $(2)$ & $(3)$ \\
\hline Treatment A & -0.016 & 0.073 & -0.021 \\
Treatment B & $(0.028)$ & $(0.107)$ & $(0.026)$ \\
& $0.050^{*}$ & 0.099 & $0.044^{*}$ \\
District: Kyegegwa & $(0.028)$ & $(0.102)$ & $(0.025)$ \\
& & & $-0.068^{*}$ \\
District: Kyenjojo & & & $(0.039)$ \\
& & & $-0.102^{* * *}$ \\
District: Kamwenge & & & $(0.036)$ \\
& & & $-0.068^{*}$ \\
District: Kasese & & & $(0.039)$ \\
& & & -0.028 \\
District: Kabarole & & & $(0.046)$ \\
District: Ntoroko & & & -0.019 \\
& & & $-0.035)$ \\
Market dummies & & & $(0.047)$ \\
District dummies & & No & Yes \\
Pseudo R & & No & Yes \\
n (Individuals) & No & 0.106 & 0.04 \\
n (Clusters) & 0.015 & 1,291 & 1,291 \\
\hline
\end{tabular}

Notes: Marginal effects from logit models. Robust Standard errors, (clustered at the market-level in (2) and (3)), in parentheses. ${ }^{*} p<0.1,{ }^{* *} p<0.05,{ }^{* * *} p<0.01$.

Table B2: Main experimental results with inverse probability weighting to correct for selection into endline

\begin{tabular}{|c|c|c|c|c|c|}
\hline & $\begin{array}{c}\text { (1) } \\
\text { Budget } \\
\text { index }(z)\end{array}$ & $\begin{array}{c}\text { (2) } \\
\text { Savings } \\
\text { index (z) }\end{array}$ & $\begin{array}{c}\text { (3) } \\
\text { Debt } \\
\text { index }(z)\end{array}$ & $\begin{array}{c}\text { (4) } \\
\text { Investment } \\
\text { index }(\mathrm{z})\end{array}$ & $\begin{array}{l}\text { (5) } \\
\text { Fin. services } \\
\text { index }(\mathrm{z})\end{array}$ \\
\hline \multirow[t]{2}{*}{ Treatment A } & 0.042 & $0.161 * *$ & $0.104^{*}$ & $0.280 * * *$ & 0.109 \\
\hline & $(0.086)$ & $(0.072)$ & $(0.057)$ & $(0.096)$ & $(0.077)$ \\
\hline \multirow[t]{2}{*}{ Treatment B } & 0.004 & 0.017 & -0.045 & 0.168 & 0.158 \\
\hline & $(0.086)$ & $(0.076)$ & $(0.076)$ & $(0.116)$ & $(0.095)$ \\
\hline$A-B=0$ (p-value $)$ & 0.672 & $0.094 *$ & $0.043^{* *}$ & 0.354 & 0.617 \\
\hline $\mathrm{R}^{2}$ & 0.109 & 0.151 & 0.009 & 0.142 & 0.131 \\
\hline Mean (SD) of $y_{t}$ in & 0.000 & 0.000 & 0.000 & 0.000 & 0.000 \\
\hline control group & $(1.000)$ & $(1.000)$ & $(1.000)$ & $(1.000)$ & $(1.000)$ \\
\hline Observations & 1,114 & 1,161 & 1,108 & 1,007 & 1,136 \\
\hline Clusters & 83 & 83 & 83 & 83 & 83 \\
\hline District FEs & yes & yes & yes & yes & yes \\
\hline \multirow{2}{*}{$\begin{array}{l}y_{(t-1)} \text { covariate } \\
\text { IPW }\end{array}$} & yes & yes & yes & yes & yes \\
\hline & yes & yes & yes & yes & yes \\
\hline
\end{tabular}

Notes: WLS regressions with inverse probability weights based on the estimation in Table B1, Column 3.

Standard errors, clustered at the market-level, in parentheses. ${ }^{*} p<0.1,{ }^{* *} p<0.05,{ }^{* * *} p<0.01$. 
Table B3: Bounds estimates for treatments A and B

\begin{tabular}{|c|c|c|c|c|c|c|c|c|c|}
\hline & $\begin{array}{c}\text { (1) } \\
\text { Extreme lower } \\
\text { bound }\end{array}$ & $\begin{array}{c}(2) \\
-0.50 \mathrm{SD}\end{array}$ & $\begin{array}{c}(3) \\
-0.25 \mathrm{SD}\end{array}$ & $\begin{array}{c}(4) \\
-0.10 \mathrm{SD}\end{array}$ & $\begin{array}{c}\text { (5) } \\
\text { Unadjusted } \\
\text { treatment effect }\end{array}$ & $\begin{array}{c}(6) \\
+0.10 \mathrm{SD}\end{array}$ & $\begin{array}{c}(7) \\
+0.25 \mathrm{SD}\end{array}$ & $\begin{array}{c}(8) \\
+0.50 \mathrm{SD}\end{array}$ & $\begin{array}{c}\text { (9) } \\
\text { Extreme } \\
\text { upper bound }\end{array}$ \\
\hline \multicolumn{10}{|c|}{ Panel A: Impact on the savings index (z) } \\
\hline Treatment A & $\begin{array}{l}-0.047 \\
(0.067)\end{array}$ & $\begin{array}{l}0.112^{*} \\
(0.065)\end{array}$ & $\begin{array}{c}0.137 * * \\
(0.066)\end{array}$ & $\begin{array}{c}0.152 * * \\
(0.066)\end{array}$ & $\begin{array}{c}0.164 * * \\
(0.071)\end{array}$ & $\begin{array}{c}0.172 * * \\
(0.066)\end{array}$ & $\begin{array}{c}0.187 * * * \\
(0.067)\end{array}$ & $\begin{array}{c}0.210 * * * \\
(0.068)\end{array}$ & $\begin{array}{c}0.274 * * * \\
(0.078)\end{array}$ \\
\hline Treatment B & $\begin{array}{c}-0.250 * * * \\
(0.075)\end{array}$ & $\begin{array}{l}-0.054 \\
(0.068)\end{array}$ & $\begin{array}{l}-0.022 \\
(0.068)\end{array}$ & $\begin{array}{l}-0.002 \\
(0.068)\end{array}$ & $\begin{array}{c}0.013 \\
(0.077)\end{array}$ & $\begin{array}{c}0.024 \\
(0.068)\end{array}$ & $\begin{array}{c}0.043 \\
(0.068)\end{array}$ & $\begin{array}{c}0.074 \\
(0.070)\end{array}$ & $\begin{array}{c}0.111 \\
(0.082)\end{array}$ \\
\hline$A-B=0(\mathrm{p})$ & $0.015^{* *}$ & $0.032 * *$ & $0.039 * *$ & $0.045^{* *}$ & $0.077 *$ & $0.054^{*}$ & $0.061^{*}$ & $0.077^{*}$ & $0.060 *$ \\
\hline $\begin{array}{l}\text { Obs. } \\
\mathrm{R}^{2}\end{array}$ & $\begin{array}{l}1,291 \\
0.415\end{array}$ & $\begin{array}{l}1,291 \\
0.161\end{array}$ & $\begin{array}{l}1,291 \\
0.153\end{array}$ & $\begin{array}{l}1,291 \\
0.151\end{array}$ & $\begin{array}{l}1,161 \\
0.152\end{array}$ & $\begin{array}{l}1,291 \\
0.153\end{array}$ & $\begin{array}{l}1,291 \\
0.157\end{array}$ & $\begin{array}{l}1,291 \\
0.167\end{array}$ & $\begin{array}{l}1,291 \\
0.589\end{array}$ \\
\hline \multicolumn{10}{|c|}{ Panel B: Impact on the investment index (z) } \\
\hline Treatment A & $\begin{array}{c}-0.485^{* * *} \\
(0.124)\end{array}$ & $\begin{array}{c}0.134 \\
(0.085)\end{array}$ & $\begin{array}{c}0.223 * * * \\
(0.082)\end{array}$ & $\begin{array}{c}0.277 * * * \\
(0.081)\end{array}$ & $\begin{array}{c}0.284 * * * \\
(0.097)\end{array}$ & $\begin{array}{c}0.349 * * * \\
(0.080)\end{array}$ & $\begin{array}{c}0.402 * * * \\
(0.080)\end{array}$ & $\begin{array}{c}0.493 * * * \\
(0.080)\end{array}$ & $\begin{array}{l}1.09 * * * \\
(0.125)\end{array}$ \\
\hline $\begin{array}{l}\text { Treatment B } \\
A-B=0(\mathrm{p})\end{array}$ & $\begin{array}{c}-0.656^{* * *} \\
(0.138) \\
0.104\end{array}$ & $\begin{array}{c}-0.016 \\
(0.099) \\
0.148\end{array}$ & $\begin{array}{c}0.087 \\
(0.096) \\
0.183\end{array}$ & $\begin{array}{c}0.150 \\
(0.095) \\
0.208\end{array}$ & $\begin{array}{c}0.168 \\
(0.119) \\
0.353\end{array}$ & $\begin{array}{c}0.232 * * \\
(0.095) \\
0.248\end{array}$ & $\begin{array}{c}0.294 * * * \\
(0.094) \\
0.282\end{array}$ & $\begin{array}{c}0.396 * * * \\
(0.095) \\
0.348\end{array}$ & $\begin{array}{c}1.18 * * * \\
(0.171) \\
0.661\end{array}$ \\
\hline $\begin{array}{l}\text { Obs. } \\
\mathrm{R}^{2}\end{array}$ & $\begin{array}{l}1,291 \\
0.186\end{array}$ & $\begin{array}{l}1,291 \\
0.119\end{array}$ & $\begin{array}{l}1,291 \\
0.118\end{array}$ & $\begin{array}{l}1,291 \\
0.119\end{array}$ & $\begin{array}{l}1,007 \\
0.144\end{array}$ & $\begin{array}{l}1,291 \\
0.123\end{array}$ & $\begin{array}{l}1,291 \\
0.128\end{array}$ & $\begin{array}{l}1,291 \\
0.138\end{array}$ & $\begin{array}{l}1,291 \\
0.202\end{array}$ \\
\hline Clusters & 83 & 83 & 83 & 83 & 83 & 83 & 83 & 83 & 83 \\
\hline District FE & Yes & Yes & Yes & Yes & Yes & Yes & Yes & Yes & Yes \\
\hline$y_{(t-1)}$ covar. & Yes & Yes & Yes & Yes & Yes & Yes & Yes & Yes & Yes \\
\hline
\end{tabular}

Notes: Standard errors, clustered at the market-level, in parentheses. ${ }^{*} p<0.1,{ }^{* * *} p<0.05,{ }^{* * * *} p<0.01$. 
Table B4: Main experimental results (OLS using only endline data)

\begin{tabular}{lccccc}
\hline & $\begin{array}{c}(1) \\
\text { Budget } \\
\text { index (z) }\end{array}$ & $\begin{array}{c}(2) \\
\text { Savings } \\
\text { index (z) }\end{array}$ & $\begin{array}{c}(3) \\
\text { Debt } \\
\text { index (z) }\end{array}$ & $\begin{array}{c}(4) \\
\text { Invest- } \\
\text { ments (z) }\end{array}$ & $\begin{array}{c}\text { Fin. } \\
\text { services } \\
\text { index (z) }\end{array}$ \\
\hline Treatment A & 0.031 & $0.200^{* *}$ & $0.099^{*}$ & $0.314^{* * *}$ & 0.094 \\
& $(0.094)$ & $(0.078)$ & $(0.055)$ & $(0.109)$ & $(0.093)$ \\
Treatment B & 0.012 & 0.048 & -0.021 & $0.231^{*}$ & 0.186 \\
& $(0.095)$ & $(0.087)$ & $(0.069)$ & $(0.136)$ & $(0.116)$ \\
\hline$A-B=0$ (p-value) & 0.843 & 0.127 & $0.076^{*}$ & 0.567 & 0.424 \\
$\mathrm{R}^{2}$ & 0.047 & 0.025 & 0.007 & 0.058 & 0.032 \\
Mean (SD) of $y_{t}$ in control group & 0.000 & 0.000 & 0.000 & 0.000 & 0.000 \\
& $(1.000)$ & $(1.000)$ & $(1.000)$ & $(1.000)$ & $(1.000)$ \\
Observations & 1,114 & 1,160 & 1,108 & 1,007 & 1,136 \\
Clusters & 83 & 83 & 83 & 83 & 83 \\
District FEs & yes & yes & yes & yes & yes \\
$y_{(t-1)}$ covariate & no & no & no & no & no \\
\hline Notes: Standard errors, clustered at the market-level, in parentheses. ${ }^{*} p<0.1,{ }^{* *} p<0.05,^{* * *} p<0.01$.
\end{tabular}

Table B5: Standard financial knolwedge score

\begin{tabular}{|c|c|c|c|}
\hline & $\begin{array}{l}\text { (1) } \\
\text { OLS }\end{array}$ & $\begin{array}{c}(2) \\
\text { Ordered logit }\end{array}$ & $\begin{array}{c}\text { (3) } \\
\text { Ordered probit }\end{array}$ \\
\hline \multirow[t]{2}{*}{ Treatment $\mathrm{A}$} & 0.155 & 0.099 & 0.165 \\
\hline & $(0.110)$ & $(0.083)$ & $(0.141)$ \\
\hline \multirow[t]{2}{*}{ Treatment B } & 0.089 & 0.062 & 0.109 \\
\hline & $(0.101)$ & $(0.078)$ & $(0.126)$ \\
\hline$A-B=0$ (p-value $)$ & 0.55 & 0.67 & 0.70 \\
\hline $\mathrm{R}^{2}$ & 0.028 & & \\
\hline Pseudo $\mathrm{R}^{2}$ & & 0.016 & 0.015 \\
\hline \multirow{2}{*}{ Mean (SD) of $y_{t}$ in control group } & 2.491 & 2.491 & 2.491 \\
\hline & $(1.531)$ & $(1.531)$ & $(1.531)$ \\
\hline Observations & 1,162 & 1,162 & 1,162 \\
\hline Clusters & 83 & 83 & 83 \\
\hline District FEs & yes & yes & yes \\
\hline$y_{(t-1)}$ covariate & yes & yes & yes \\
\hline
\end{tabular}

Notes: Dependent variable is the financial knowledge sumscore (cf. Appendix C) at the time of the endline survey. (1) shows OLS results. (2) shows results from an ordered-logit model. (3) shows results from an orderedprobit model. Standard errors, clustered at the market-level, in parentheses. ${ }^{*} p<0.1,{ }^{* *} p<0.05,{ }^{* * *} p<0.01$. 


\section{Appendix C: Measuring financial literacy}

Financial literacy is typically measured through a set of survey-items that measure financial knowledge (cf. Huston 2010, p. 303). In a second step, the scores on these dichotomous items (true/false) are summed up to generate a scale of financial knowledge to serve as a proxy for the latent trait "financial literacy". There are standard questions used for the assessment of financial literacy in developed economies (cf. Knoll and Houts 2012; Lusardi and Mitchell 2014, p. 10) and Cole et al. (2011) were the first to translate and adapt these questions to a developing economy context for their study of financial education and the demand for financial products in Indonesia. While these and similar survey items have been widely used in the literature on financial education in developing economies (e.g. Carpena et al. 2011; Sayinzoga et al. 2016), their psychometric properties have not been adequately assessed. This may be surprising since knowledge development is seen to be one of the primary goals of these types of financial education interventions (cf. Skimmyhorn 2016) and the need for a valid measure of financial literacy appears evident.

Thus, we study the psychometric properties of these items and propose an alternative approach to generate valid financial literacy scores for individual respondents: Following Knoll and Houts' (2012) discussion of items used in the assessment of financial knowledge in large-scale household surveys, we use "item response theory" (IRT) to create a valid and reliable scale of financial literacy. IRT is a family of models widely used in educational and psychological measurement (see Rasch 1960 and Lord 1980 for key contributions to this literature). A popular model used to design psychological measurement-scales is the twoparameter logistic model (2PLM) (cf. Birnbaum 1968). Here, the probability of an individual $j$ to solve the item $i$ is defined as

$$
P\left(x_{i j}=1 \mid \theta_{j}\right)=\frac{\exp \left\{a_{i}\left(\theta_{j}-b_{i}\right)\right\}}{1+\exp \left\{a_{i}\left(\theta_{j}-b_{i}\right)\right\}}
$$

with 


$$
\theta_{j} \sim N(0,1)
$$

where $a_{i}$ and, $b_{i}$ are the discrimination and difficulty parameters of item $i$ respectively, and $\theta_{j}$ representing the latent trait (e.g. financial literacy) of individual $j$. Thus, the discrimination parameter $a_{i}$ describes how well item $i$ discriminates people of lower and higher ability $\left(\theta_{j}\right)$, and $b_{i}$ corresponds to the point on the latent scale $(\theta)$ where $P\left(x_{i}=1 \mid \theta\right)=0.5$ (i.e. the point on the latent scale where an individual has a greater possibility to score the item than indicated by chance). Since we assume $\theta$ to have a mean of zero by definition, an item $i$ is relatively easy to solve if $b_{i}<0$, and an item $i$ is relatively hard to solve if $b_{i}>0$. This model requires the assumption of local independence among items (solving an item must not be conditional upon solving another item) and $\theta$ to be unidimensional. While local independence is given by the design of the items and implementation into the survey instruments, we tested the assumption of unidimensionality through a polychloric factor analysis. Indeed, only one factor is estimated with an eigenvalue $>1$ and, thus, the assumption of a unidimensional $\theta$ appears to be met by the items included in the scale (cf. Figure $\mathrm{C} 1$ in Appendix $\mathrm{C})$. To arrive at parameter estimates for $a_{i}$ and, $b_{i}$, as well as to predict $\theta_{j}$ for all respondents in the dataset, we estimate equation (1) with five binary items that form the final financial knowledge scale. Standard errors are clustered at the level of randomization (markets).

Table $\mathrm{C} 1$ shows the exact wording, discrimination and difficulty for the final set of five items. The items are ordered by their ability to discriminate in ascending order. Thus, item 1 is the least discriminating $\left(a_{1}=0.981\right)$ and item 5 is the most discriminating $\left(a_{5}=\right.$ 1.629). The difficulty ranges from -0.569 (item 2) to 0.463 (item 3). A graphic representation of these item characteristics is depicted in Figure $\mathrm{C} 2$ which shows the trace line for each item included in the scale. Item 3 is most difficult (furthest to the right) while item 2 appears to be easiest. Regarding the discrimination, it is obvious that the trace line for item 5 has the 
steepest slope while the slope of item 1 is most gradual. Another way to represent the features of each item is to plot the item information functions. Figure $\mathrm{C} 3$ shows the item information functions for each item. Figure C4 relates the latent trait back to the sumscores of items solved: Using the critical values of the z-distribution (-1.96 and 1.96) it appears that $95 \%$ of randomly selected individuals would solve between 0.451 and 4.51 items with a respondent of average ability $(\theta=0)$ scoring 2.56 (two or three) out of five items. Turning to the overall reliability of the scale, Figure C5 shows that the scale is most precise at the mean of $\theta$ with smallest standard errors close between -0.1 and 0 . Finally, we standardize the scale to have a mean of zero and a standard deviation of one for the control group: Figure C6 shows the full distribution of the estimated ability $(\theta)$ for all individuals in our dataset at baseline.

\section{References in Appendix C}

Birnbaum, A. 1968. Some latent trait models and their use in inferring an examinee's ability. Statistical Theories of Mental Test Scores, F. M. Lord and M. R. Novick (ed.), Reading, MA: Addison-Wesley, 395-479.

Carpena, F., Cole, S., Shapiro, J., and Zia, B. (2011). Unpacking the causal chain of financial literacy. World Bank Policy Research Working Paper 5798.

Cole, S., Sampson, T., and Zia, B. (2011). Prices or knowledge? What drives demand for financial services in emerging markets? Journal of Finance, 66(6): 1933-1967.

Knoll, M. A. Z. and Houts, C. R. (2012). The financial knowledge scale: An application of item response theory to the assessment of financial literacy. Journal of Consumer Affairs, 46(3):381-410.

Lord, F. M. (1980). Applications of Item Response Theory to Practical Testing Problems. Mahwah, NJ: Lawrence Erlbaum.

Lusardi, A. and Mitchell, O. S. (2014). The Economic Importance of Financial Literacy: Theory and Evidence. Journal of Economic Literature 52 (1), pp. 5-44.

Rasch, G. (1960). Probabilistic Models for Some Intelligence and Attainment Tests. Copenhagen: Danish Institute of Educational Research.

Sayinzoga, A., Bulte, E. H., and Lensink, R. (2016). Financial literacy and financial behaviour: Experimental evidence from rural Rwanda. Economic Journal, 126(594): 15711599.

Skimmyhorn, W. L., Davies, E. R., Mun, D., and Mitchell, B. (2016). Assessing financial education methods: Principles vs. rules-of-thumb approaches. Journal of Economic Education, 47(3): 193-2. 
Table C1: Items and their psychometric properties of the final FL-scale

\begin{tabular}{|c|c|c|c|c|c|c|}
\hline Item & Topic & Question and response options & $\begin{array}{l}a_{i} \\
(\mathrm{SE})\end{array}$ & $\begin{array}{c}b_{i} \\
(\mathrm{SE})\end{array}$ & $\begin{array}{c}\% \\
\text { correct } \\
\text { baseline }\end{array}$ & $\begin{array}{c}\% \\
\text { correct } \\
\text { endline }\end{array}$ \\
\hline 1 & Diversification & $\begin{array}{l}\text { Is it riskier to plant...? } \\
\text { A) multiple crops or } \\
\text { B) one crop } \\
\text { Y) Don`t know } \\
\text { Z) Refuse to Answer }\end{array}$ & $\begin{array}{l}1.092 \\
(0.166)\end{array}$ & $\begin{array}{l}-0.569 \\
(0.104)\end{array}$ & 62.28 & 64.52 \\
\hline 2 & Inflation & $\begin{array}{l}\text { If you have UGX. } 100,000 \text { in a savings } \\
\text { account earning } 1 \% \text { interest per annum, } \\
\text { and prices for goods and services rise } 2 \% \\
\text { over a } 1 \text {-year period, can you buy } \\
\text { A) more than, } \\
\text { B) less than, } \\
\text { C) or the same amount of goods in } 1 \text { year } \\
\text { as you could today, with the money in the } \\
\text { account?" } \\
\text { Y) Don't know } \\
\text { Z) Refuse to Answer }\end{array}$ & $\begin{array}{l}1.692 \\
(0.258)\end{array}$ & $\begin{array}{l}-0.375 \\
(0.085)\end{array}$ & 60.50 & 67.16 \\
\hline
\end{tabular}

\begin{tabular}{|c|c|c|c|c|c|c|}
\hline 3 & $\begin{array}{l}\text { Interest rate } \\
\text { (loan) }\end{array}$ & $\begin{array}{l}\text { If you were offered a loan with } 5 \% \\
\text { monthly interest rate and a loan with } 20 \% \\
\text { annual interest rate, which loan would } \\
\text { offer better value? } \\
\text { A) } 5 \% \text { monthly interest rate } \\
\text { B) } \mathbf{2 0 \%} \text { annual interest rate } \\
\text { Y) Don`t know } \\
\text { Z) Refuse to Answer }\end{array}$ & $\begin{array}{l}1.346 \\
(0.149)\end{array}$ & $\begin{array}{l}0.130 \\
(0.061)\end{array}$ & 46.79 & 48.88 \\
\hline
\end{tabular}

\begin{tabular}{|c|c|c|c|c|c|c|}
\hline 4 & $\begin{array}{l}\text { Interest rate } \\
\text { (loan) }\end{array}$ & $\begin{array}{l}\text { Suppose you need to borrow } 500,000 \\
\text { UGX. Two people offer you a loan. } \\
\text { Which loan represents a better deal for } \\
\text { you? } \\
\text { A) One loan requires you to pay back } \\
600,000 \text { UGX in } 1 \text { month. } \\
\text { B) The second loan requires you to pay } \\
\text { back in } 1 \text { month 500,000 UGX plus } \\
\text { 15\% interest. } \\
\text { Y) Don`t know } \\
\text { Z) Refuse to Answer }\end{array}$ & $\begin{array}{l}0.981 \\
(0.152)\end{array}$ & $\begin{array}{l}0.274 \\
(0.107)\end{array}$ & 44.46 & 43.78 \\
\hline 5 & $\begin{array}{l}\text { Compound } \\
\text { interest }\end{array}$ & $\begin{array}{l}\text { Suppose you borrow } 100,000 \text { UGX at an } \\
\text { interest rate of } 2 \% \text { per month, with no } \\
\text { repayment for } 3 \text { months. After } 3 \text { months, } \\
\text { do you owe } \\
\text { A) less than. } 102,000 \text { UGX, } \\
\text { B) exactly. } 102,000 \text { UGX, } \\
\text { C) or more than } \mathbf{1 0 2 , 0 0 0 ~ U G X ? ~} \\
\text { Y) Don't know } \\
\text { Z) Refuse to Answer }\end{array}$ & $\begin{array}{l}1.218 \\
(0.146)\end{array}$ & $\begin{array}{l}0.463 \\
(0.087)\end{array}$ & 39.27 & 52.94 \\
\hline
\end{tabular}

Notes: $\mathrm{N}=1,291$ at baseline. Results from fitting a 2PLM to the 5 items. Standard errors are clustered at the market-level. Items are coded to be binary. The correct response is coded to be equal to one. Wrong answers and response options $\mathrm{Y}$ ) and $\mathrm{Z}$ ) are coded to be equal to zero. 


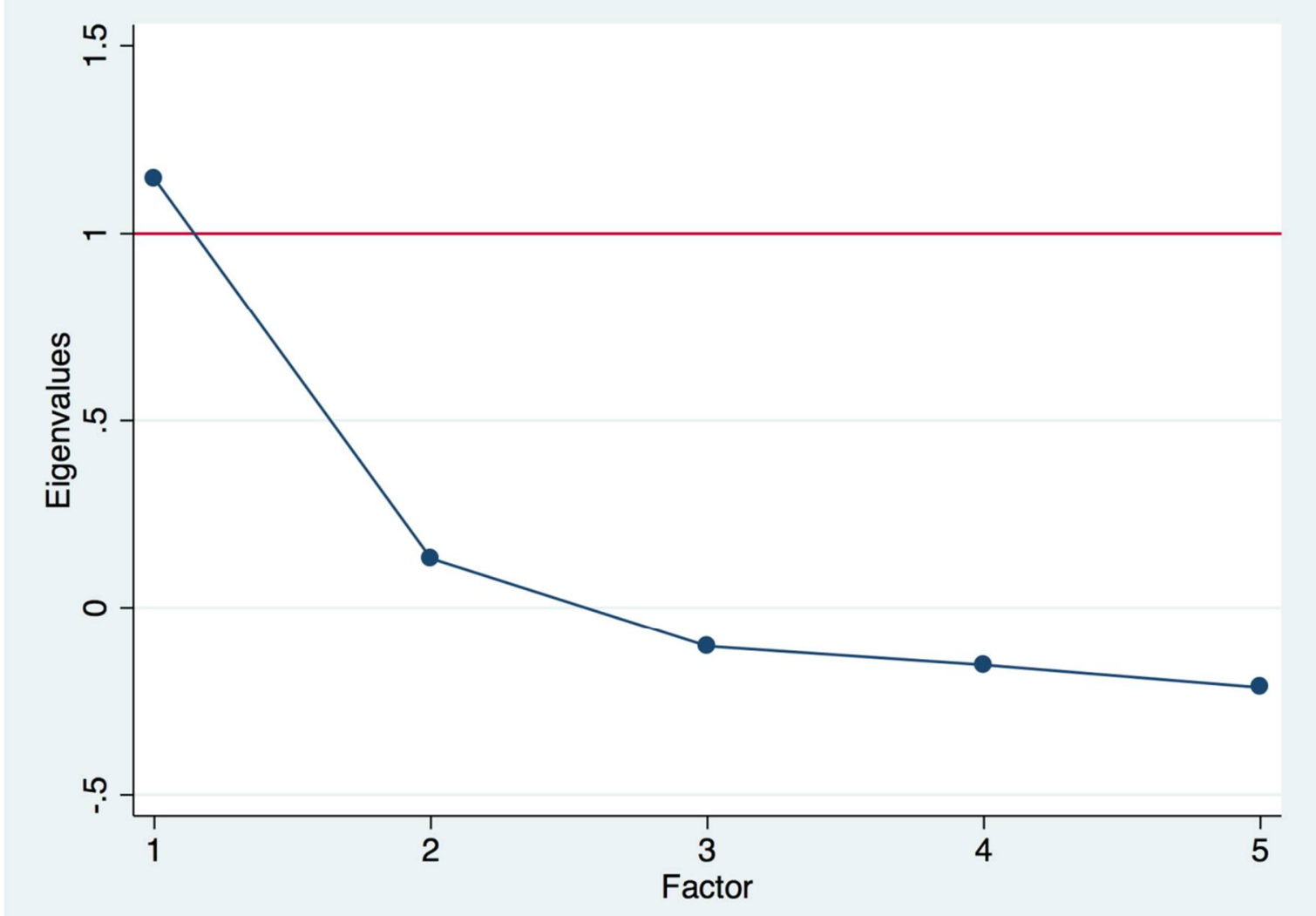

Figure C1: Screeplot of eigenvalues by factor after factor analysis

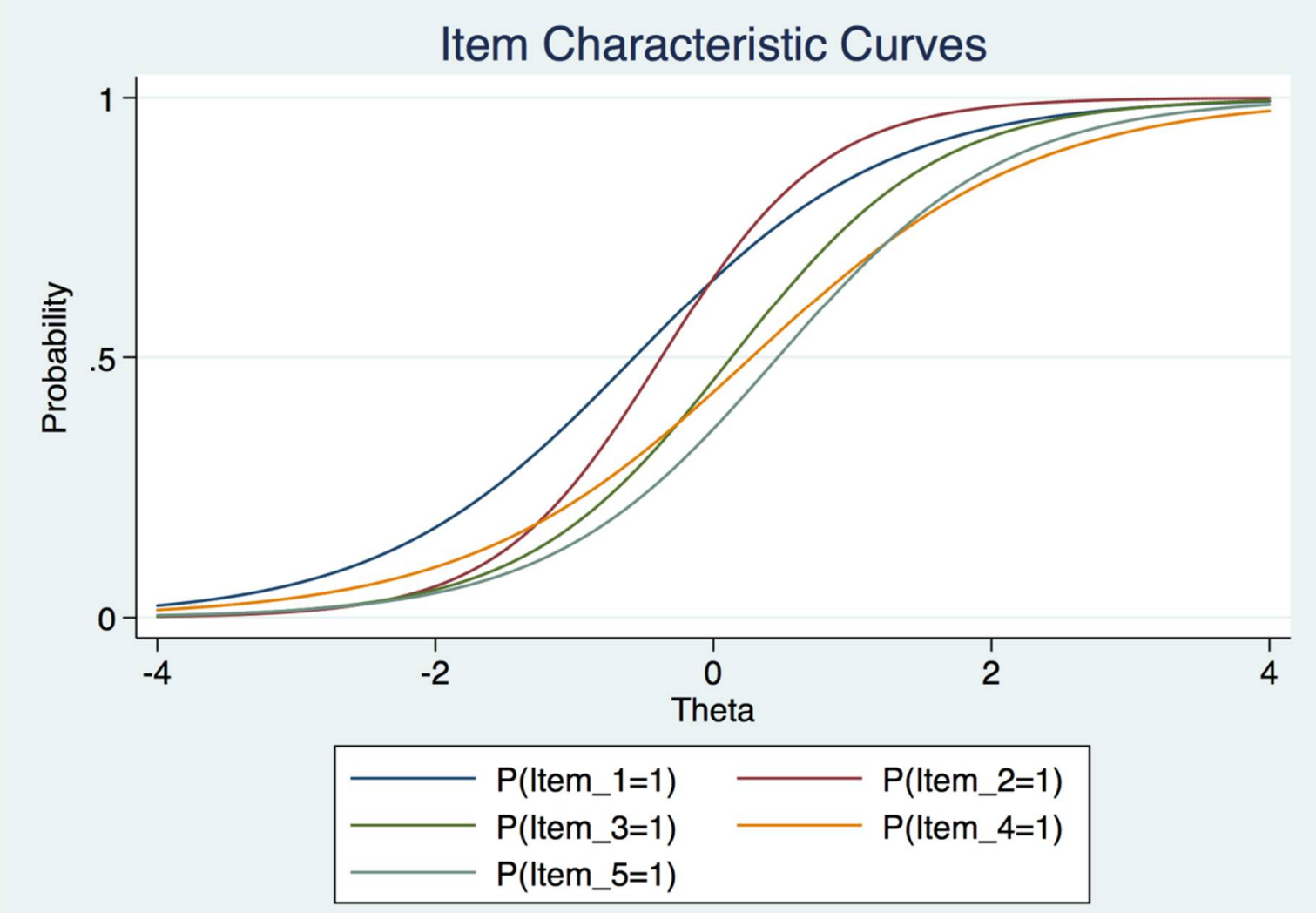

Figure C2: Item characteristic curves for the 2PLM financial literacy scale 


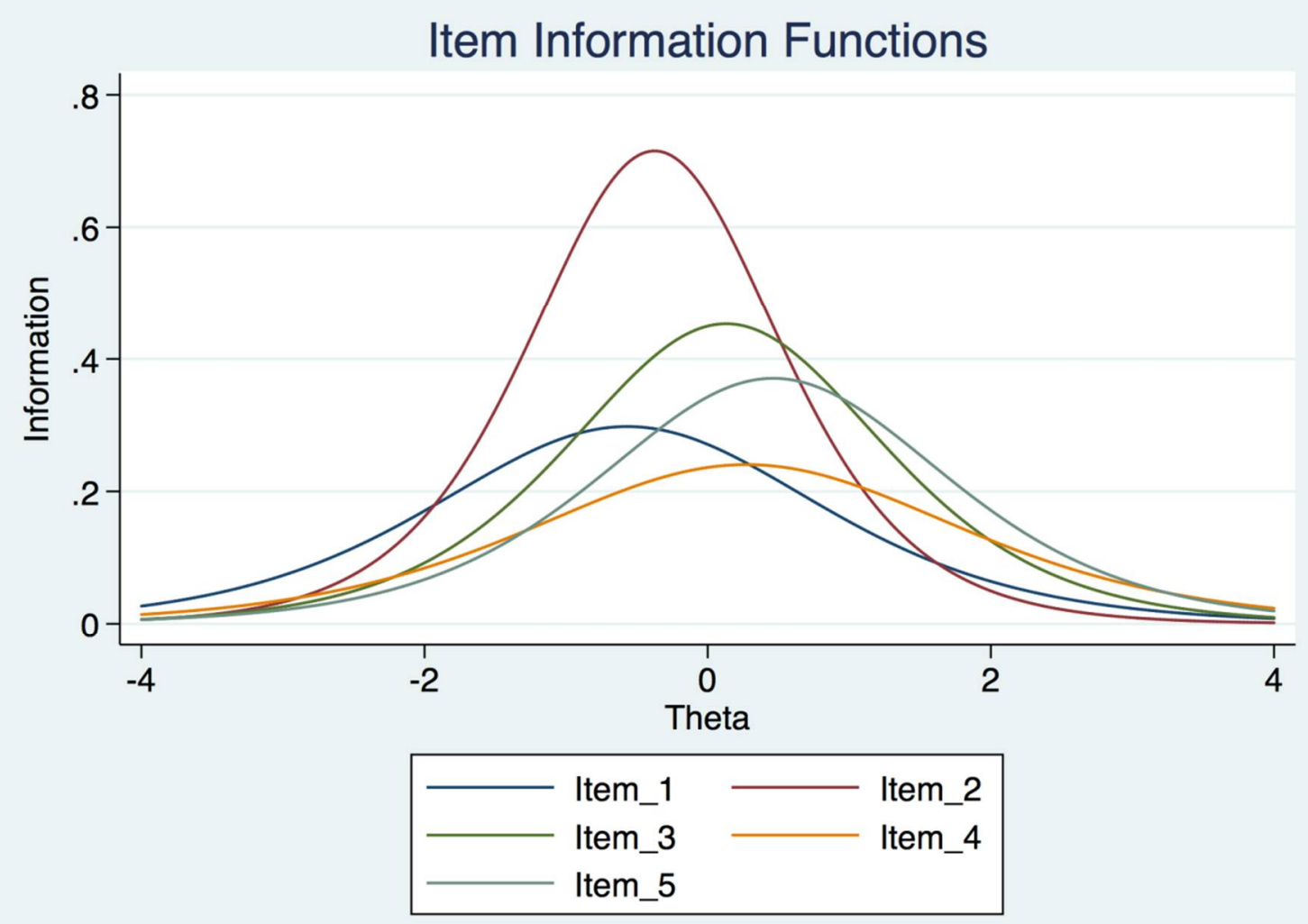

Figure C3: Item information functions for the 2PLM financial literacy scale

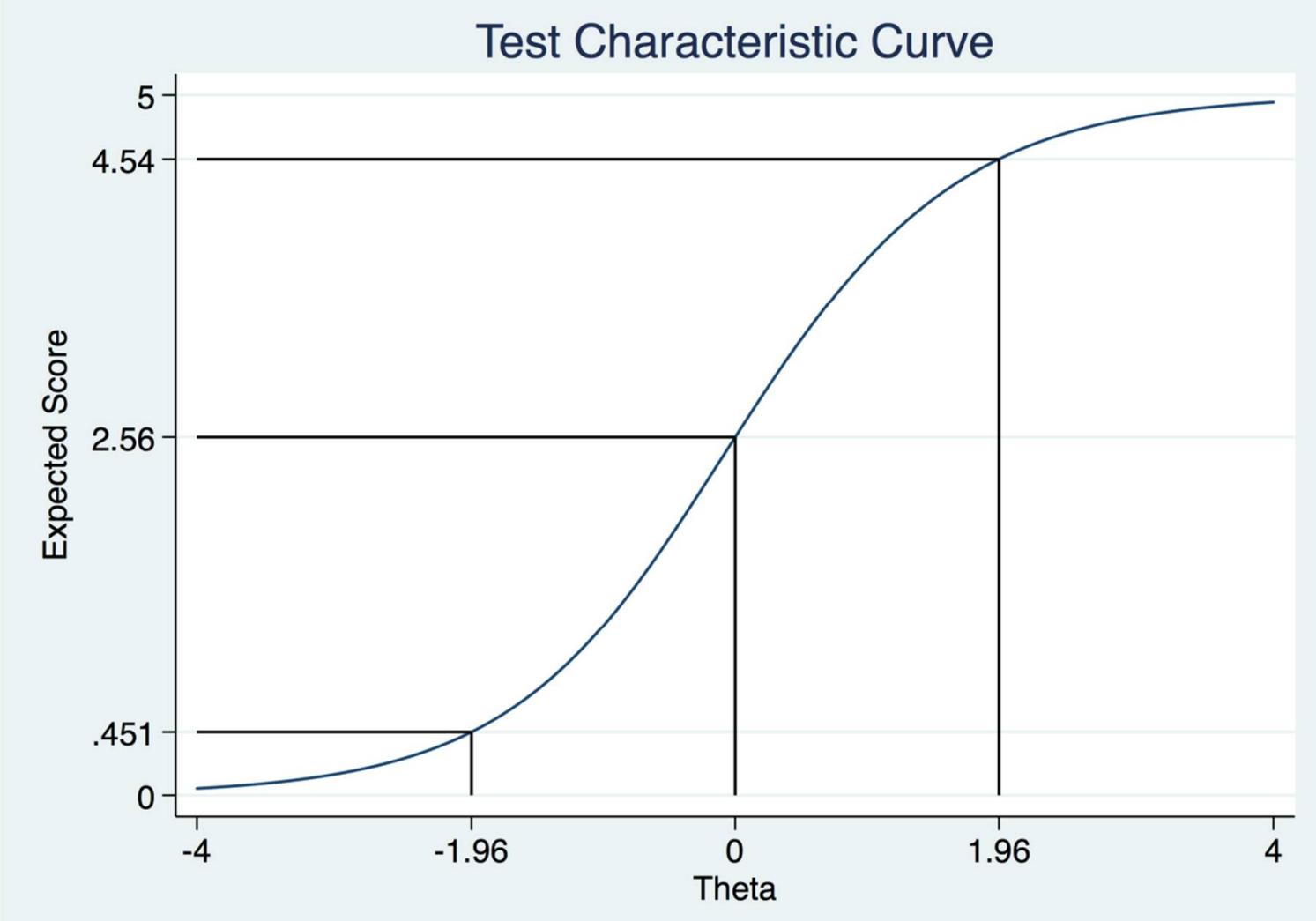

Figure C4: Test characteristic curve for the 2PLM financial literacy scale 


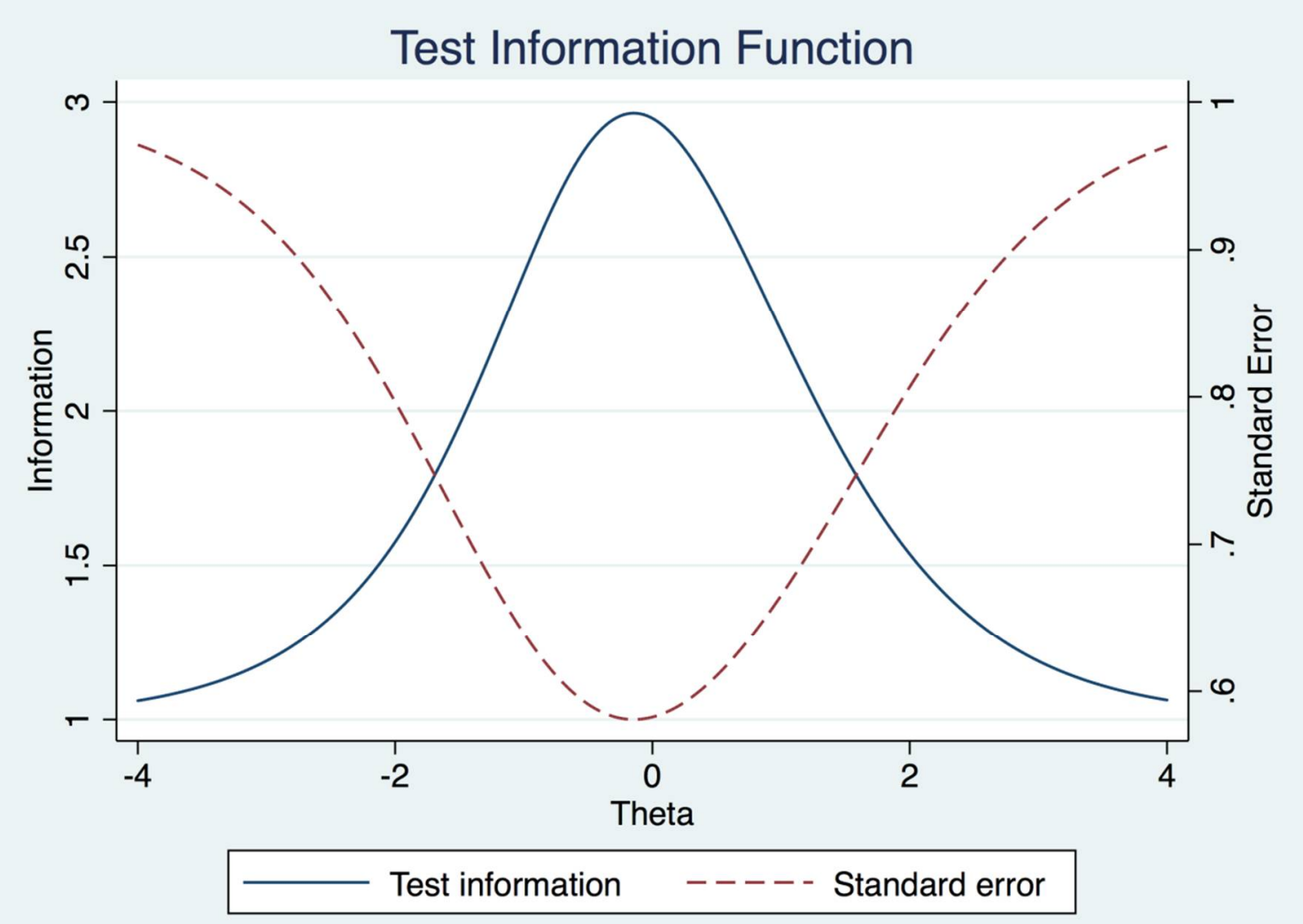

Figure C5: Test information function for the financial literacy scale

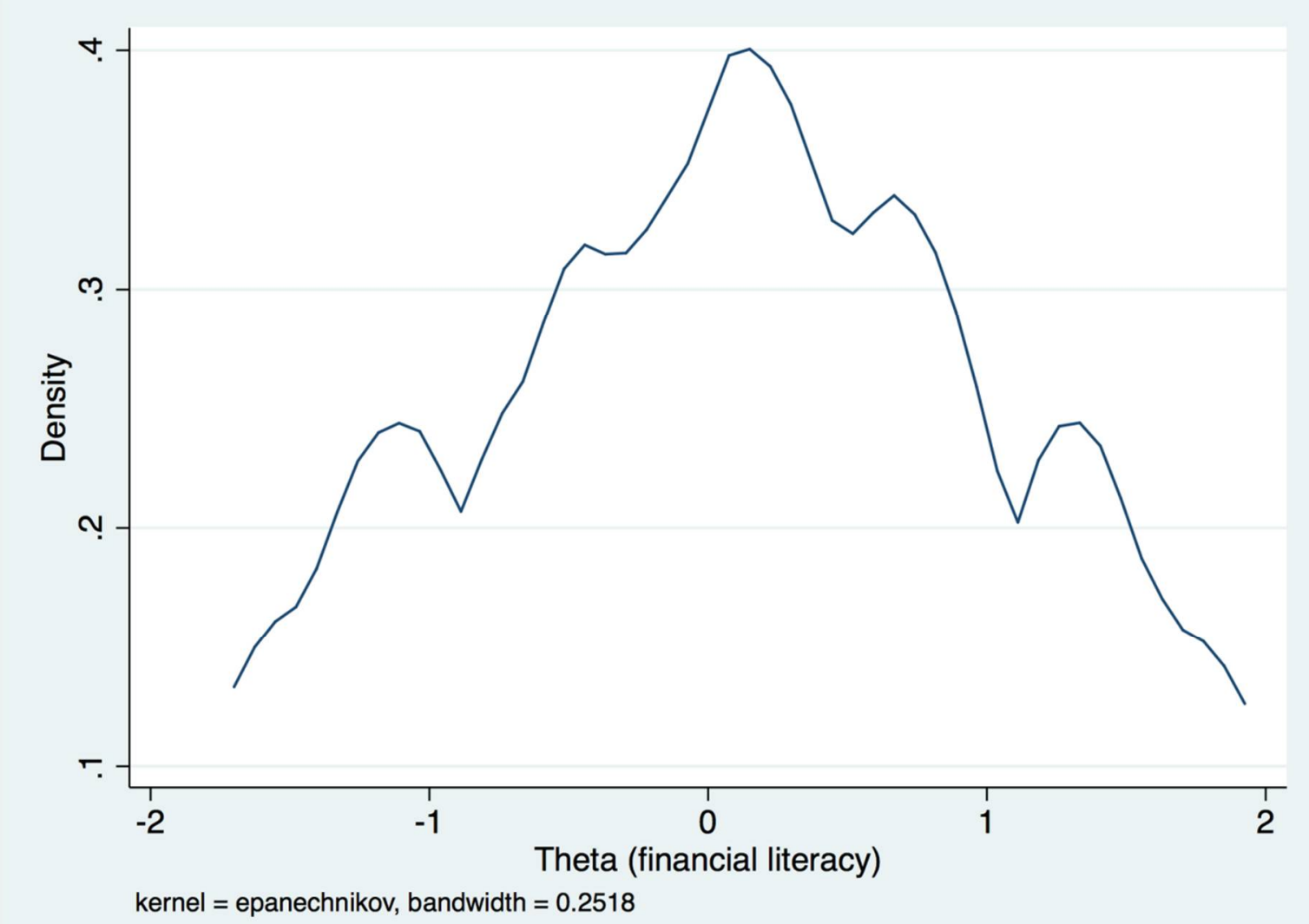

Figure C6: Distribution of standardized financial literacy IRT-scores at baseline 